\title{
The development of the intention to study of pupils from different social backgrounds in non-traditional pathways to higher education
}

\author{
Claudia Schuchart $^{1}$ (D) Benjamin Schimke ${ }^{1}$
}

Received: 25 September 2020 / Accepted: 17 January 2022 / Published online: 2 March 2022

(c) The Author(s) 2022

\begin{abstract}
In this paper we investigate whether and if so why different pathways to higher education (HE) have an effect on the development of the intention to study and its motivational factors of pupils from different social backgrounds. In Germany as well as in many other countries, non-traditional pathways-mostly vocational oriented schools, but also comprehensive schools-lead to eligibility for HE. Drawing on the theory of planned behaviour (Ajzen in Organ Behav Human Decis Process 50:179-211, 1991); Fishbein and Ajzen (Belief, attitude, intention and behaviour. An introduction to theory and research, Addison-Wesley Publishing Company, Reading, MA, 1975) and empirical results, we assume that the intention to study and motivational factors (=attitudes towards HE, the perceptions of expectations of relevant others, control beliefs) of pupils in vocationally oriented pathways develop less favourably than those of pupils in comprehensive schools, and that for pupils in vocationally oriented pathways the effects of social backgrounds on intentions and motivational factors become stronger due to school-type specific college-going cultures. Our database consists of the responses of 7133 pupils in comprehensive schools and vocationally oriented two-year and three-year pathways to $\mathrm{HE}$ at the beginning (t1) and the end (t2) of upper secondary education. We use Propensity Score Matching to disentangle selection and socialization effects. Our results show that among vocationally oriented pathways, only two-year pathways divert pupils from HE, partly due to decreasing expectations of relevant others and attitudes towards HE. In contrast, the intention to study and the motivational factors among pupils in direct as well as in three-year vocationally oriented pathways remain stable during upper secondary education. No differential effects of the pathways on pupils from different social backgrounds could be observed. Thus, vocationally oriented pathways do not in general divert their pupils from HE, but if they do so, all pupils are affected regardless of social background.
\end{abstract}

The study was financed by the Federal Ministry of Education and Research (BMBF/Germany).

Extended author information available on the last page of the article 
Keywords Intention to study · Social background · Higher education · Upper secondary education - Theory of planned behaviour - School socialization · Educational aspirations

\section{Introduction}

In many educational systems, both traditional—mostly academic_-and non-traditional-mostly vocationally oriented-pathways in upper secondary education lead to the eligibility to enter Higher Education (HE) (see for instance Ichou \& Vallet, 2011 for France; Breen \& Jonsson, 2000 for Sweden; Holm et al., 2013 for Denmark; Buchmann \& Park, 2009 and also Griga \& Hadjar, 2013 for an overview). Research has suggested that this type of horizontal differentiation increases the effect of social background on the decision for HE for the following reasons: Significant proportions of pupils from lower social strata obtain the eligibility to study via non-traditional pathways (Buchholz \& Schier, 2015; Holm et al., 2013; Schindler, 2014), but graduates from these pathways are less likely to enter HE than graduates from traditional pathways to HE (Breen \& Jonsson, 2000; Hillmert \& Jacob, 2003; Holm et al., 2013; Ichou \& Vallet, 2011; Kerckhoff et al., 2001; Müller \& Schneider, 2013; Reimer \& Pollak, 2010; Schindler, 2014; Shavit \& Müller, 2006). Non-traditional pathways may therefore divert from HE (Shavit et al., 2007), and this may particularly be true for pupils from lower social strata (Schindler, 2014; Holm et al., 2013; Bol \& van de Werfhorst 2013; Hillmert \& Jacob, 2010; Becker \& Hecken, 2009; Pfeffer, 2008; Shavit \& Müller, 2006; Müller \& Shavit, 1998). In this paper the theory of planned behavior is used (Ajzen, 1991; Fishbein \& Ajzen, 1975) in order to better understand how non-traditional pathways to the eligibility to study in upper secondary education can influence the transition to $\mathrm{HE}$ of pupils from different social backgrounds.

This study is a contribution to existing research in the following ways: Although some authors have shown that different pathways to HE influence social inequalities in the transition to HE differently, we know little about the mechanisms that lead to this result. Our study focuses on the development of the intention to study in upper secondary education and on the motivational factors that underlie its formation (Ajzen, 1991; Fishbein \& Ajzen, 1975). We understand the intention to study as realistic appraisal, thus distinguishing it from idealistic aspirations (Haller, 1968; Morgan, 2006). The intention to study is one of the most important predictors of the decision for HE (Wisconsin model, Sewell et al., 1969). Furthermore, there has so far not been much research that focuses on the effects of school tracks in lower secondary education on the development of socially unequal intentions to study (Buchmann \& Dalton, 2002; Buchmann \& Park, 2009; Parker et al., 2016). This research is cross-sectional in nature and thus it is mostly correlative relationships between the intention to study and other explanatory variables that have been investigated. The present study uses data collected at the beginning and the end of upper secondary education, and it can thus analyse how different pathways to HE influence the development of the motivational factors that finally lead to the intention to study. 


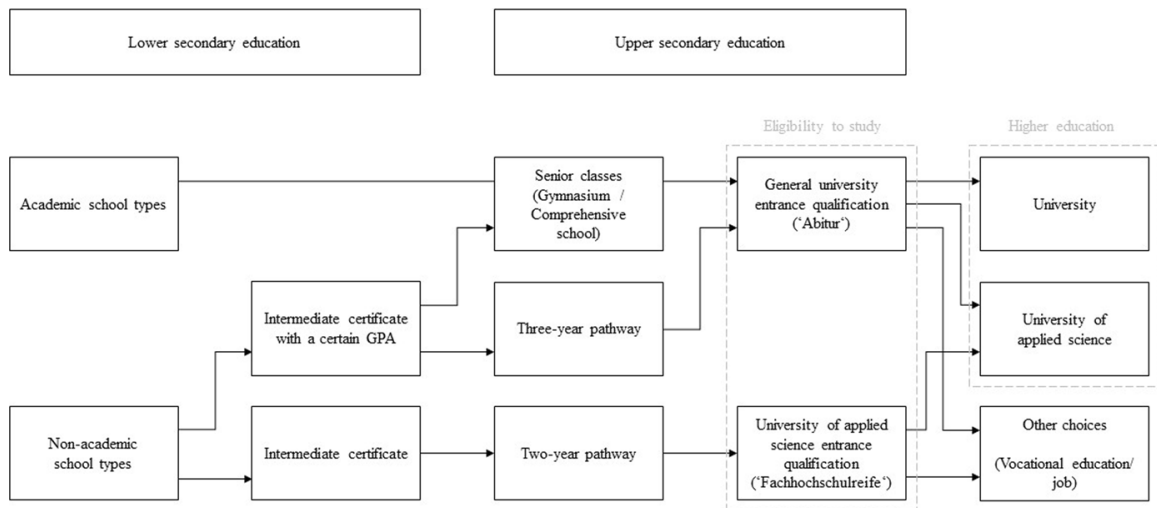

Fig. 1 Traditional and non-traditional pathways to HE in Germany (simplified)

We use the example of Germany, where traditionally in lower secondary education (years 5-10) an early selection takes place (Hadjar \& Gross, 2016) into distinct secondary school tracks that lead to eligibility for HE such as the Gymnasium, and school types that do not (Fig. 1). However, during the 1960s and the 1970s, the recognition of considerable social inequalities regarding access to the Gymnasium led to an opening up of academic education to socially diverse groups of pupils. Amongst other measures, this was achieved by the introduction of new academic and new vocationally oriented pathways to HE. First, within the academic system in a number of federal states, comprehensive schools were established, which, unlike Gymnasiums, accept a heterogeneous pupil body in terms of academic ability. Comprehensive school pupils who meet certain achievement requirements can, after year 10, move on to upper secondary education leading to the eligibility to study. The curriculum for these pupils is the same as in Gymnasiums. Second, within the vocational education system of all the federal states, pathways to the eligibility to study were established for pupils who graduate from non-academic school types with an intermediate certificate. General knowledge as well as basic vocational knowledge is taught in these pathways, but some of the programmes also award a vocational qualification. If pupils graduate from non-academic school types with a certain grade point average, they can follow a three-year pathway to general eligibility for university entrance ('Abitur'). Pupils with a lower grade point average can follow a two-year pathway to eligibility for a university of applied sciences ('Fachhochschulreife'). In the two-tiered higher education system in Germany, universities are more theoretically oriented, and universities of applied sciences are more practically oriented. However, for graduates of these two types of university, there is only a slight difference in terms of income or position in the labour market (Leuze, 2011; Schuchart \& Schimke, 2019).

These new pathways to HE helped to broaden access to HE and to reduce social inequalities in the acquisition of the eligibility to study (Schindler, 2017). In the $2016 / 17$ school year, of all eligibilities to study obtained in non-traditional pathways, $33 \%$ were awarded in three-year vocationally oriented pathways to $\mathrm{HE}, 53 \%$ in 
two-year vocationally oriented pathways to $\mathrm{HE}$, and $14 \%$ to pupils at comprehensive schools (with considerable variation in the proportions among the various federal states, Statistisches Bundesamt, 2018). Although some studies suggest that it in particular vocationally oriented pathways that tend to contribute to an increase in social inequalities in the transition to HE, the findings of Schindler (2014) suggest that for Germany this is true for all non-traditional pathways to HE, including comprehensive schools. However, it is not clear whether non-traditional pathways are chosen by pupils who already do not have the intention to enter HE or whether nontraditional pathways divert pupils from HE, in particular pupils from non-privileged backgrounds. Furthermore, little is known about whether different pathways to HE have the same or different influences on pupils from privileged and non-privileged social backgrounds. This study focuses on the influence of non-traditional pathways to HE-namely academic (=comprehensive schools) and vocationally oriented pathways - on the development of the intention to study and its motivational factors of pupils from different social backgrounds.

The paper is organized as follows: We use the theory of planned behaviour (TPB) to explain (a) how intentions to study are formed as a result of motivational factors and how they are influenced by (b) social background and (c) different pathways to HE, and we develop a number of hypotheses (2.1-2.3). These hypotheses are tested using a representative longitudinal survey of 7133 pupils at comprehensive schools and vocationally oriented pathways in North Rhine-Westphalia (Germany) in upper secondary education $(3+4)$. The results are then discussed in the final Sect. 5.

\section{Theoretical and empirical background}

\subsection{Social background and the intention to study}

In this paper, we are interested in the development of the intention to study in upper secondary education as a function of the social background and the pathway to HE. Numerous studies have provided results on the reasons for the effects of social background on the intention to study. Although we know that the participation in pathways to HE interacts with social background (Brint \& Karabel, 1989; Schindler, 2017), we do not yet have a clear picture of how a particular pathway influences the effects of the social background on the intention to study. In order to contribute to closing this research gap, we draw on the TPB (Ajzen, 1988, 1991; Fishbein \& Ajzen, 1975), a theory in the field of rational choice theories. Following the TPB, the intention to perform a decision is influenced by three major factors (see also Fig. 3): a favourable or unfavourable evaluation of the consequences of the decision (attitude), perceived social pressure to perform the decision (subjective norm), and the perceived obstacles that may prevent the performance of the decision (perceived behavioural control). Empirical studies in the field of educational outcomes show that these factors determine to a large extent the intention to perform an educational decision (Ajzen \& Madden, 1986; Davis et al., 2002; Dewberry \& Jackson, 2018; Petzold \& Moog, 2018; Watermann \& Maaz, 2010). The major factors develop from corresponding sets of specific behaviour-related beliefs, which are measured within 
the framework of an expectancy-value model (Ajzen, 1991). Although the TPB does not explicitly cover developmental processes, it implies that the major factors and the intention can change as the decision comes closer (Ajzen, 1991; Niepel et al., 2018) and individuals become more aware of obstacles (Ajzen, 1991). Although educational intentions and major factors are rather stable in upper secondary education (Niepel et al., 2018; Zhang et al., 2011), they are not fixed but are influenceable by - among other factors - educational achievement (Rosenbaum, 2001) and enrolment at different types of college (Alexander et al., 2008).

The TPB itself does not include assumptions on the impact of social background. However, it has been shown that social background affects the major factors, which in turn form an intention (Ajzen, 1991; Davis et al., 2002; Schüz et al., 2017; Watermann \& Maaz, 2010). The results of Watermann and Maaz (2010) and Maaz (2006) indicate that differences between graduates from advantaged and less advantaged social backgrounds regarding their intention to study and their transition to HE were mediated only by the major factors, with the latter group having less favourable attitudes towards HE, perceiving less social pressure and feeling they have less control over obstacles. Differences in specific beliefs about HE according to social background have been found by other studies that did not use the TPB but whose results can be systematized according to the TPB's three major factors. Attitude: Compared to pupils from privileged social backgrounds, pupils from nonprivileged backgrounds expect smaller economic benefits from a university degree (Erikson \& Jonsson, 1996; Kerr et al., 2015; Perna, 2008), they believe less strongly that a university degree leads to a secure job (Schindler \& Reimer, 2010) and they find the kind of academic work that is required in HE less interesting (ibid.). Norm: Family members, friends, classmates and even teachers and counsellors have lower study expectations of pupils from non-privileged backgrounds compared to pupils from other backgrounds (e.g. Byun et al., 2012; Erickson et al., 2009). Perceived behavioural control: Pupils from less privileged social backgrounds perceive their academic performance to be weaker than pupils from privileged backgrounds (even if performance is controlled for, Schindler \& Reimer, 2010), they know considerably less about application requirements, available funding and degree programmes at universities (Barone et al., 2017; Castleman \& Page, 2013; Constantine et al., 2006; Ehlert et al., 2017), and they perceive the (direct and indirect) costs of HE to be beyond their means (Barone et al., 2018; Peter \& Zambre, 2017; Schindler \& Lörz, 2012). Less favourable attitudes, subjective norms and perceived behavioural control of pupils from lower social strata compared to pupils from higher social strata will lead to weaker intentions to study and finally to lower transition rates to $\mathrm{HE}$ after graduation from upper secondary education.

Although it is well known that social background influences beliefs and the intention to study up to a certain point in time, little is known about how these effects of social background change over time. Some studies show that pupils from nonprivileged backgrounds are, at the end of lower secondary education or at the beginning of upper secondary education, less certain about their study intentions than pupils from privileged backgrounds, and as a result, their intention to study or to graduate from HE develop less favourably than those from privileged backgrounds (Alexander et al., 2008; Croll, 2009; Finger, 2016; Gutman \& Schoon, 2012). This 
development has been associated with the increasing awareness of pupils from nonprivileged backgrounds of poor school performance and limited financial means (Gutman \& Schoon, 2012; Rosenbaum, 2001; Trusty, 2000), the perception of general constraints of HE (Finger, 2016), or the perception of occupational expectations regarding the benefits of HE (Daniel \& Watermann, 2018). These beliefs can be assigned to the TPB's major factor "perceived behavioural control". Against this background, we formulate hypothesis 1: The influence of social background on the intention to study increases in upper secondary education, mainly due to an increasing gap in perceived behavioural control and attitudes between pupils from different social backgrounds.

\subsection{Pathways to HE and the intention to study}

It must be noted that the strict stratification in lower secondary education is associated with strong social selection (Schneider \& Tieben, 2011), and non-traditional educational pathways to the eligibility to study are mostly attended by pupils who had previously attended a non-academic type of school. The intention to study may already be influenced by individual and school characteristics in lower secondary education (Buchmann \& Dalton, 2002; Buchmann \& Park, 2009; Parker et al., 2016).

However, in the following, we focus on how different non-traditional pathways to $\mathrm{HE}$ in upper secondary education can provide different socialization contexts that may influence the intention to study and the major factors that lead to the intention to study. Of the various mechanisms considered in previous literature (Dreeben \& Barr, 1988), we focus on the "college-going culture"1 of schools (Engberg \& Gilbert, 2014; Robinson \& Roksa, 2016), which we understand as intertwined with school composition (McDonough, 1997).

Central characteristics of the college-going culture are the academic norms of a school (degree of preparation for college), its study, counselling and guidance practices, and the study-oriented expectations of teachers, head teachers and counsellors (Engberg \& Gilbert, 2014; Robinson \& Roksa, 2016). These characteristics develop in interactive adaptation to the goals and tasks of a school and the norms and expectations of the pupil body (McDonough, 1997; Palardy, 2015; Reay, 1998; Reay et al., 2001). The intention to study of pupils is also communicated among peers as an implicit mutual expectation to study (Blau, 1960) and is thus part of the study culture of a school. Therefore, schools with a strong college-going culture motivate even less ambitious pupils for HE. Studies have shown that controlling for individual characteristics, pupils are more likely to develop an intention to study and move on to $\mathrm{HE}$ if they attend a school which attaches more importance to study counselling and guidance than other schools, fosters an academic climate in which teachers and counselling staff are clearly oriented towards the transition to HE, and

\footnotetext{
${ }^{1}$ In order to ensure comparability with other research, we use the term "college-going culture", even though graduates from upper secondary education in Germany move on to study at universities and not at colleges.
} 
where the average level of the intention to study of peers is high (Engberg \& Gilbert, 2014; Hill, 2008; Palardy, 2015; Robinson \& Roksa, 2016). The impact of the elements that form the college-going culture on the intention to study of individual pupils should be moderated by a related development of attitudes, norms and behavioural control.

However, in countries with horizontal stratification in upper secondary education as in Germany, the "college-going culture" of a school is more influenced by the goals and tasks of the pathway to $\mathrm{HE}$ and its selection criteria than by the school itself and its particular pupil body (Schuchart, 2019). For instance, similar selection criteria apply for the upper secondary education level of comprehensive schools and three-year pathways, and the achievement requirements are lower for two-year pathways. Since there is a correlation between achievement and educational plans (Sewell et al., 1969), pupils in two-year pathways may have lower intentions to study than pupils at comprehensive schools and pupils in three-year pathways. Moreover, the tasks and goals of different pathways to HE are differently defined. For instance, in the German federal state in which the present study took place, the goal of upper secondary education in comprehensive schools is clearly to prepare their upper secondary education pupils to enter higher education (Schulministerium NRWa). By contrast, "preparation for vocational training" is the goal defined for vocationally oriented schools (Schulministerium NRWb), which provide general education and basic vocational education. The findings of Schuchart (2019) indicate that these differences in the definition of goals in combination with a pathway-specific pupil body are associated with different levels of college-going culture. At comprehensive schools, teachers and head teachers communicate higher expectations regarding the preparation and aptitude of their pupils for HE, offer more study and orientation guidance and recommend vocational training options less frequently than teachers and head teachers at vocationally oriented schools. These findings indicate that the college-going culture is more strongly developed at comprehensive schools than at vocationally oriented schools. The degree of "college-going culture" in a certain pathway may influence the effect of social background on the intention to study: The stronger the college-going culture of a pathway is, the more successful it may be in influencing the intention to study and its motivational factors of an individual student and, consequently, the weaker may be the effects of social background (Meyer 1969; see Buchmann \& Dalton, 2002 for expectations from parents and peers (='subjective norms'); but see Roth, 2017 for contradicting results).

Therefore, hypothesis 2 is: The intention to study of pupils in upper secondary education in comprehensive schools develops more favourably than the intention to study of pupils in the vocationally oriented pathways to HE. These differences are associated with a corresponding development of attitudes, subjective norms and perceived behavioural control.

\subsection{Pathways and social background}

Little is known about how different institutional socialization contexts influence the effect of social background on the intention to study. In 2.1 we expected a general 
increase in the effects of social background on the intention to study in upper secondary education, and in 2.2 a stronger college-going culture in comprehensive schools compared to vocationally oriented pathways to HE. We have also suggested that in particular a strong college-going culture may weaken the effects of social background on the intention to study of pupils at comprehensive schools. Against this background, hypothesis 3 is: The effect of social background on the intention to study develops less strongly in comprehensive schools compared to vocationally oriented pathways to $H E$. Since we expect the institutional socialization context to have an impact on all three major factors (2.2), we assume that this differential development is associated with a different development of attitudes towards $H E$, subjective norms and perceived behavioural control as a function of the pathway to $H E$.

\section{Method}

The goal of this study is to investigate the effect of social background on the development of the intention to study within different institutional contexts of upper secondary education. This makes some demands on the database and the methodological procedure. In the following, we first describe the database and the variables used (3.1-3.2). Then we discuss the limitations of the database and how we overcome them (3.3-3.4).

\subsection{Data collection}

Within the framework of the project "Equity in upper secondary education: An intervention study to support the intention to study" (funded by the Federal Ministry of Education and Research (Funding number: 01JC1109)), data were collected in 11 comprehensive schools and 39 vocationally oriented schools (=vocationally oriented pathways) in North Rhine-Westphalia (NRW, Germany). In the 2016/17 school year in NRW, $13.4 \%$ of all eligibilities to study were obtained at comprehensive schools and $24.9 \%$ in vocationally oriented, most of them in two-year pathways and thus for a university of applied sciences.

In the first step of the sampling procedure, schools were chosen at random to represent all the comprehensive and vocationally oriented schools in North RhineWestphalia in 2011. In the selected schools, all the pupils who attended year 11 of upper secondary education were asked to participate in the study. We consider twoyear and three-year vocationally oriented pathways to HE (pathways that lead to the 'Fachhochschulreife' and the 'Abitur' respectively). These pathways do not lead to a vocational qualification.

In the first wave (t1) of the survey, $\mathrm{N}=6142$ datasets from pupils were collected at the very beginning of upper secondary education (first two weeks of year 11 in 2012), of whom $N=3358$ pupils were evaluated again at the very end of upper secondary education ( $\mathrm{t} 2$ ). The second wave was conducted in 2014 for pupils in the two-year pathway and in 2015 for pupils in the three-year pathway to HE. The missing data are due to school or course changes, illness, school excursions, school 
dropouts or other absences. Additionally, $\mathrm{N}=991$ pupils answered the questionnaire at $\mathrm{t} 2$ without having participated at $\mathrm{t} 1$ because they were not present at $\mathrm{t} 1$ due to the reasons mentioned above. Thus, our database consisted of $\mathrm{N}=7133$ pupils. To avoid the problems that arise from using only those cases with data at both $\mathrm{t} 1$ and $\mathrm{t} 2$, we decided to impute the missing data (see Sect. 3.3 for further explanation).

\subsection{Variables}

The intention to study (see the description and the distribution of the variable at $\mathrm{t}$ and $\mathrm{t} 2$ in Table 2) represents an average of three items (e.g. "I strongly intend to study", on 7-point scales). These were developed according to Ajzen's recommendations for the recording of an intention (see http://people.umass.edu/aizen/tpb.html, accessed on 15.01.2022). With a reliability of Cronbach's $\alpha=0.93$ (t1) and $\alpha=0.96$ (t2), this scale has very good internal consistency.

Major factors Attitude was assessed at $\mathrm{t} 1$ and $\mathrm{t} 2$ on the basis of three items asking participants to indicate (on 7-point scales) whether they perceived having a university degree as useful or not useful, important or unimportant, and sensible or not sensible. Three items measured the subjective norm by asking participants whether people who are important to them expected them to study. Responses were averaged; high scores indicate positive attitudes and a large degree of social pressure. Perceived behavioural control was assessed on the basis of two items on whether participants thought they could overcome any obstacles that might prevent them from studying and whether this would be easy or difficult for them. High scores in averaged results indicate low perceived behavioural control. Cronbach's $\alpha$ is 0.79 at both (t1) and (t2) (subjective norm), 0.87 (at t1) and 0.88 (at t2) (attitude towards $\mathrm{HE}$ ), and 0.66 (perceived behavioural control, both waves), indicating an internal consistency ranging from moderate to good.

Social background In order to capture different mechanisms by which social origin can influence the major factors and the intention to study, we considered two components of social origin (Bukodi \& Goldthorpe, 2013): a) whether at least one parent holds a university degree, and b) socioeconomic status. By including whether at least one parent holds a university degree, we wanted to capture a cultural background that is characterized by education-related norms and values. Furthermore, parental experience of HE is an important source of knowledge. We took the International Socio-economic Index of Occupational Status (ISEI, Ganzeboom \& Treimann 2003) of the parent with the highest ISEI to capture the economic resources of a family (Bukodi \& Goldthorpe, 2013). These two components of social origin were measured at $\mathrm{t} 1$ and reported by the pupils.

Covariates In order to test hypotheses 2 and 3, we had to disentangle the effects of sorting into different pathways and socialization as an effect of these pathways. We decided to balance the samples from different pathways using Propensity Score Matching (PSM-for further details see Sect. 3.3). For the PSM procedure, we used variables measured at $\mathrm{t} 1$ that were likely to drive pupils into different pathways to HE (see Table 1): Whether a pupil attended an academic or a non-academic school type in lower secondary education clearly affects his or her choice of pathway in 


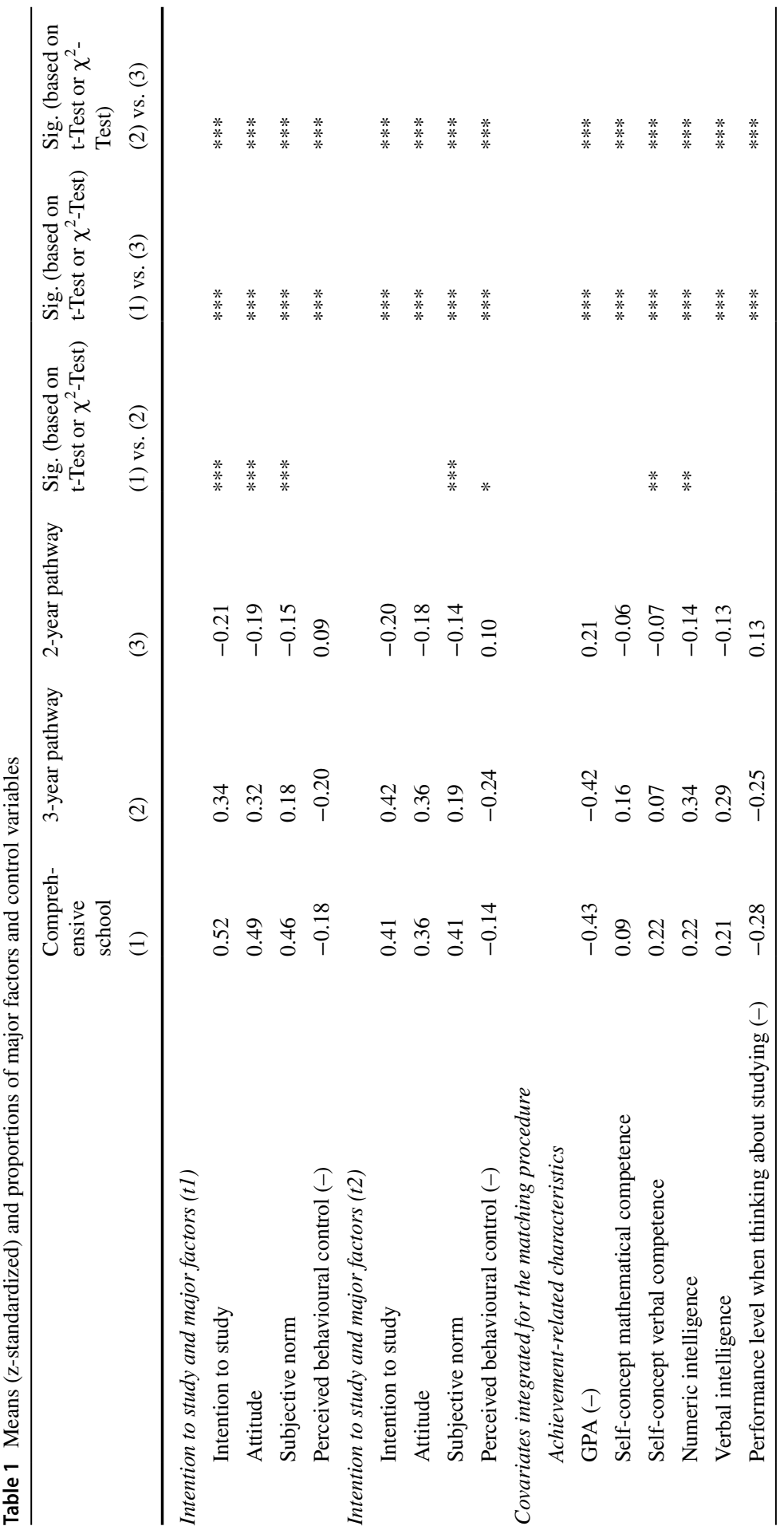




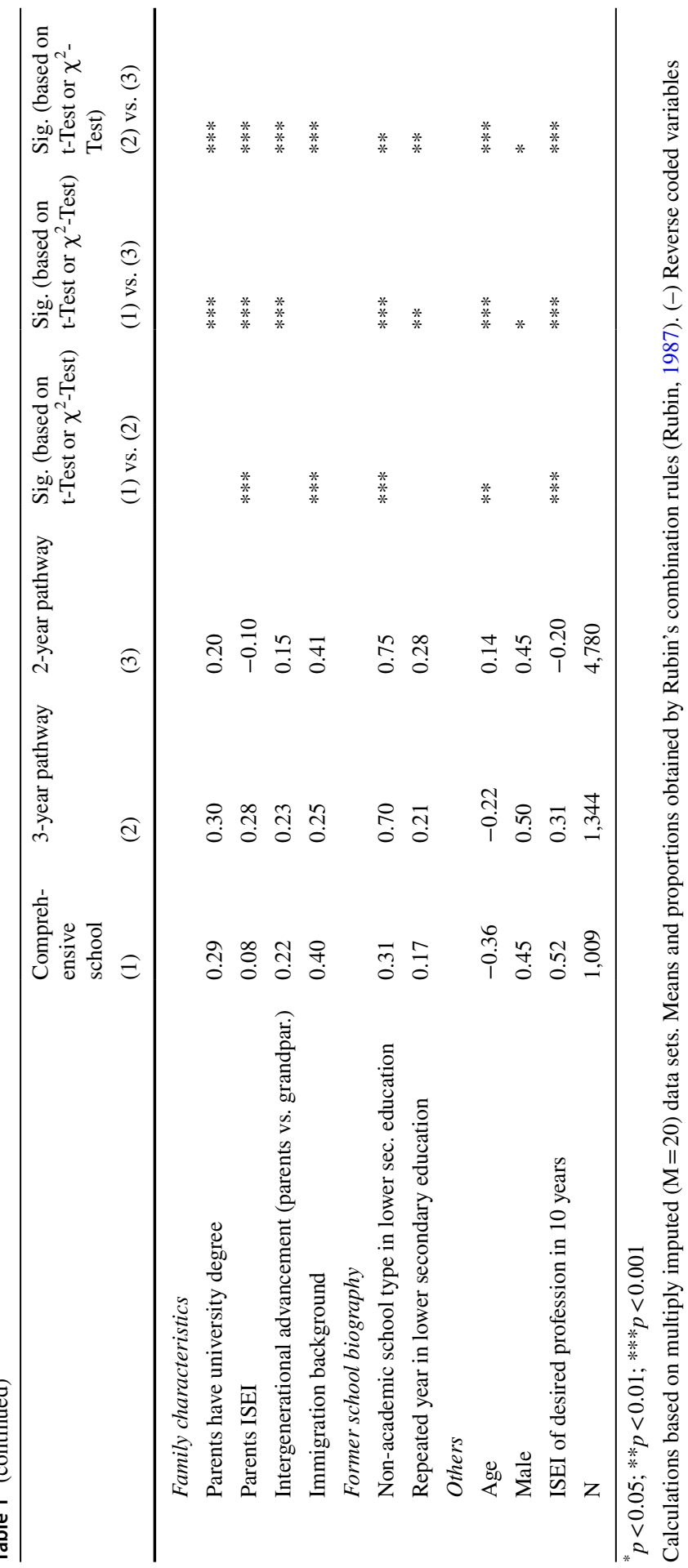


upper secondary education and his or her intention to study. Other important prerequisites are achievement and achievement-related characteristics (Sewell et al., 1969). We used average grades in mathematics, German and the first foreign language at the end of lower secondary education ( $\mathrm{t} 1$; central exams; lower scores indicate better grades), the self-concept regarding mathematical and verbal competences (short version of Marsh, 1992), and verbal and numerical intelligence (Heller et al., 1985). In addition, we used the self-assessed performance level when thinking about studying (Heine, Quast \& Beuße 2010), which has been found to correlate strongly with study intentions (Daniel \& Watermann, 2018). As well as the educational background of the parents, we also considered other family characteristics such as the immigration background ( $1=\mathrm{I}$ and/or my parents were not born in Germany) and the intergenerational educational mobility regarding university education (grandparents to parents). Finally, we considered gender, age, class repetition during lower secondary education (yes/no), and the socioeconomic status of the desired occupation in 10 years time (coded in terms of the ISEI). See Table 2 in the appendix for further information on all the variables.

\subsection{Analysis strategy}

\subsubsection{Unit-nonresponse and item-nonresponse}

While item-nonresponse is a problem in all kinds of surveys, the panel design of our study raises additional attrition problems. Both unit-nonresponse and item nonresponse lead to missing data and in the best case to inefficiency (when the MCAR assumption holds, see below). In our case, ignoring the missing information is likely to bias our estimation results, because item-nonresponse is correlated with at least some observed variables, and unit-nonresponse (at t2) is not independently distributed either. Thus, we decided to multiply impute the missing data for the following reasons: First, analysing the complete cases $(\mathrm{N}=2973)$ instead of the whole sample would at least lead to inefficient parameter estimates. Second, preliminary analysis of the missing structure for the major factors of our analysis (see Table 2) led to the rejection of the missing completely at random (MCAR) assumption, so ignoring these results would also lead to biased estimates (Carpenter \& Kenward, 2014; Enders, 2010; Rubin, 1987; van Buuren, 2012). Missing information depends on at least a few observed variables (MAR), so multiple imputation is an appropriate technique to deal with the missing data. Incomplete variables were imputed in 20 datasets using a fully conditional specification approach (e.g. van Buuren et al., 2006).

In Table 3 we give information on descriptive comparisons in the intention to study, major factors and social background using complete cases versus multiply imputed datasets. The slightly different results, especially for the intention and major factors at $\mathrm{t} 2$, are expected since the analyses of the missing structure suggested a higher non-response probability for pupils with less favourable attributes. This also indicates a violation of the MCAR assumption and therefore supports our decision to impute the missing information. See in addition Table 4 for an overview 


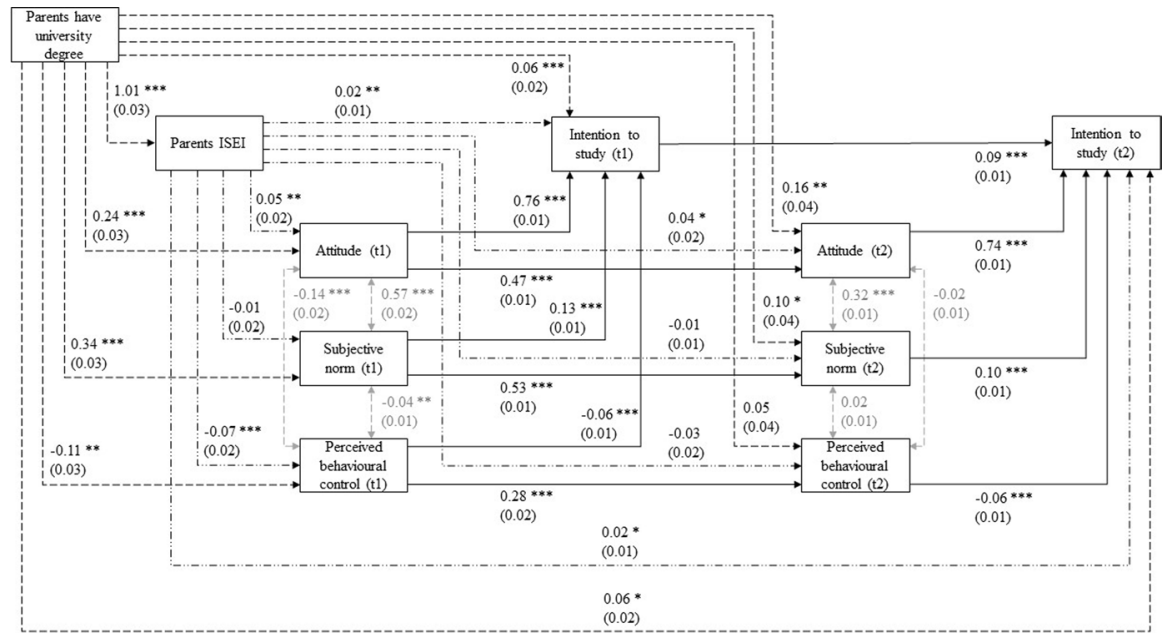

Fig. 2 Structural equation model. $* p<0.05 ; * * p<0.01$; $* * * p<0.001$. Note: Calculations based on multiply imputed $(M=20)$ datasets. Structural equation model conducted on each imputed dataset separately and standardized estimation results obtained by Rubin's combination rules (Rubin, 1987). Fit Indices: $\mathrm{TLI}=0.94, \mathrm{CFI}=0.98$, RMSEA $=0.05$, calculated as suggested by (Enders and Mansolf 2018) Control variables: grades at $\mathrm{t} 1$ and $\mathrm{t} 2$

of intercorrelations between the dependent variables, independent variables and covariates that underlie the imputation model.

The results presented below are based on the recovered sample $(\mathrm{N}=7,133)$. All analyses were done for each imputed dataset separately, with estimates and standard errors combined afterwards using Rubin's rules (Rubin, 1987).

\subsubsection{Path model}

First of all, we used path modelling to test the general model of the TPB and to analyse the direct effect of social background on the major factors and the intention to study (hypothesis 1). We specified direct paths from social background to attitude towards HE, subjective norm, perceived behavioural control and intention to study at $\mathrm{t} 1$, and to the same characteristics at $\mathrm{t} 2$ (see Fig. 2). We controlled for grades at t 1 and $\mathrm{t} 2$ (see Table 1 for conditional standardized means). Since pupils at the same school are likely to be similar to each other with regard to their attitudes and beliefs, the cluster structure of the data must be taken into account by correcting the standard errors, which was done using the vce(cluster) option of the analysis software Stata 14.

\subsubsection{Propensity score matching (PSM)}

In order to test the hypotheses of the influence of pathway to $\mathrm{HE}$ on the intention to study and on the motivational factors, we have to disentangle the effects of track placement and track-specific socialization (Gamoran, 2010). For this reason, 
Propensity Score Matching (PSM) was chosen as a suitable technique. This approach addresses selectivity issues by explicitly taking the assignment process (choosing an educational pathway to $\mathrm{HE}$ ) into account before analysing treatment effects (the socialization effect due to different educational environments). The general idea is to construct from non-experimental data treatment and control groups which are alike in terms of observed characteristics by matching treated individuals to their non-treated statistical twins and comparing their mean difference in the outcome afterwards (Rosenbaum \& Rubin, 1983). Propensity Score Matching thereby overcomes problems that arise from selectivity bias by eliminating initial differences in the social composition of pupils in different pathways. It has two major advantages over regression-based techniques. First, the two steps in this procedure, through the separation of treatment and outcome models, lead to more transparency with regard to all the content-based and statistical decisions (e.g. Gangl, 2010; Rubin, 2006). Second, the non-parametrical matching approach-once the assignment process is modelled-does not rely on the linearity assumption, which is especially important for our purpose (Gangl, 2010). The observations differ with respect to many of the fundamental variables (see Table 1), so linearity is a very strong assumption in a multidimensional space with few overlaps. PSM deals with these common support problems by taking only those treated observations into account which can be matched to similar non-treated counterparts.

For the matching procedure, we selected covariates which are theoretically associated a) with the selection of a certain pathway in upper secondary education and b) with the intention to study at $\mathrm{t} 2$ (see 3.2 "Covariates"). Since these variables must be unaffected by the socialization process during upper secondary education, they were measured at $\mathrm{t} 1$ (Table 1).

\section{Results}

\subsection{General model and direct effects of the social background (hypothesis 1 )}

The results of the structural equation model are shown in Fig. 2. Coefficients of control variables are not shown for reasons of clarity. The major factors at t1 strongly influence the major factors at $\mathrm{t} 2$, which in turn are of utmost importance for the intention to study at $\mathrm{t} 2$. The intention to study increases slightly at $\mathrm{t} 2$ compared to t1 (see Table 1). A strong stability of major factors and intention has been found by other studies as well (Niepel et al., 2018; Zhang et al., 2011; see also Alexander et al., 2008). As in other studies which use the TPB to explain educational outcomes (Ajzen \& Madden, 1986; Davis et al., 2002; Schuchart, 2012), attitudes towards HE have the strongest influence on the intention to study, followed by subjective norms and perceived behavioural control.

The results also show that at $\mathrm{t} 1$ pupils from academic and socioeconomically more privileged backgrounds report more favourable attitudes towards HE, subjective norms and behavioural control and a stronger intention to study than pupils from non-academic and socioeconomically less privileged backgrounds. In hypothesis 1 we stated that the impact of social background on the intention to study increases 
over time due to an increasing gap between pupils from different backgrounds regarding perceived behavioural control and attitudes. The findings show, that perceived behavioural control does not develop depending on social background, but attitudes towards $\mathrm{HE}$ and subjective norms develop more favourably among pupils from privileged social backgrounds compared to pupils from non-privileged backgrounds. The impact of the social background at $\mathrm{t} 2$ is stronger on attitudes than on subjective norms, and attitudes are in turn most strongly associated with the intention to study. However, we also find that, even controlling for major factors at $\mathrm{t} 2$, pupils from socioeconomically and educationally privileged social backgrounds strengthen their intention to study compared to pupils from non-privileged backgrounds.

In the following, we analyse whether comprehensive schools and vocationally oriented pathways differ (a) in their influence on the development of the intention to study and the motivational factors that precede this intention (hypothesis 2), and (b) in their influence on the effects of social background on the intention to study and its major factors (hypothesis 3) using PSM. First, we describe the differences in the student composition of the pathways to HE, and second, the general results of the PSM procedure. Third, we report the results of PSM according to hypotheses 2 and 3.

\subsection{Differential effects of pathways to HE}

\subsubsection{Differences between pathways in the unmatched sample}

Table 1 provides the means and proportions of covariates that may have been the basis for the choice of different pathways. We highlight here only some results: The respondents at the comprehensive schools and in the vocationally oriented threeyear pathway are mostly similar regarding achievement-related characteristics such as GPA, cognitive ability and self-concept, whereas pupils in two-year pathways differ in these characteristics from pupils in the two other pathways. Since the academic requirements to enter upper secondary education via comprehensive schools or three-year pathways are the same but lower for the admission to two-year pathways, this is an expected result.

There are differences between all three pathways regarding socioeconomic and ethnic composition. The proportion of pupils from less advantaged socioeconomic and immigration backgrounds is lowest in three-year pathways. This may reflect the fact that after lower secondary education, this pathway is more likely to be chosen not only by the more able but also by the more privileged pupils, whereas less privileged (and less able) pupils tend to choose two-year pathways. However, the greatest differences concern the intention to study and the major factors at $\mathrm{t} 1$, with the highest levels among pupils at comprehensive schools and the lowest among pupils in the two-year pathway. These differences may reflect selection effects and socialization effects during lower secondary education. Thus, although pupils at comprehensive schools are on average from less privileged backgrounds than pupils in the three-year pathway, they have a stronger intention to study, more favourable attitudes towards HE, subjective norms and behavioural control. 


\subsubsection{The PSM procedure}

In all, the comparison of pupils from the different educational pathways leads to a significant overall mean bias. The mean standardized bias for pupils from comprehensive schools and the three-year pathway is 17\% (see Table 5). This bias is even greater for the other comparisons (39\% and 33\%). The robustness of the matching results is tested by various model specifications and options. In a first step, the assignment is modelled using binary logit models separately for each comparison. Afterwards, nearest neighbour matching with different numbers of potential control observations is conducted as well as kernel matching with different kernel functions. These matching procedures have different focal points in (1) bias reduction and (2) efficient estimation, and therefore they seem to complement each other very well for robustness checks (Caliendo \& Kopeinig, 2008). NN-matching is performed with the "replacement" option to ensure suitable matching partners even in areas of thin common support. To account for multiply used control observations, frequency weights were used in all the analyses. To decide whether a matching partner is similar in terms of the propensity score, the caliper was set at approximately $\mathrm{c}=0.05 * \mathrm{SD} \approx 0.01$, and in a second approach the caliper setting was even stricter- $\mathrm{c}=0.05 * \mathrm{SD} / 2 \approx 0.005$ (e.g. Retelsdorf et al., 2012). The mean standardized biases after matching (between 2 and 5\%) indicate successful balancing procedures and thus seem to justify the conditional independence assumption independently of the model specification (see Table 5).

Some of the observations in the comprehensive schools (up to 26\%) cannot be matched to adequate controls, so the sample reduction is considerable in some analyses. This is due to different propensity score distributions for pupils in the comprehensive schools and the vocationally oriented pathways (Figures 5, 6, and 7).

\subsubsection{Results of PSM}

We analyse the matched data in order to test our hypothesis

Differences between pathways (hypothesis 2): The charts in Fig. 3 show the results of PSM with one-to-one-matching (with replacement) and a caliper of 0.01 . This procedure is likely to provide the most unbiased estimate for differences between pathways (see full table in Appendix Table 6). For comparisons between comprehensive schools and one of the vocationally oriented pathways, the former serves as the treatment group. We also compare the two vocationally oriented pathways, and in this case the three-year pathway serves as the treatment group. Pupils are matched for each pairwise comparison separately.

As can be seen in Fig. 3, there are no significant differences between the threeyear pathway to HE and the comprehensive schools for all the variables considered (chart a). However, the intention to study develops less favourably in the two-year pathway compared to the comprehensive school and the three-year pathway (charts $b$ and $c$ ). Furthermore, attitudes towards HE and the perceived behavioural control of pupils in the two-year pathway develop less favourably compared to those in the three-year pathway. Hypothesis 2, which claimed there are differences between comprehensive schools and the vocationally oriented pathways to 
(a) Comprehensive school

3-year pathway

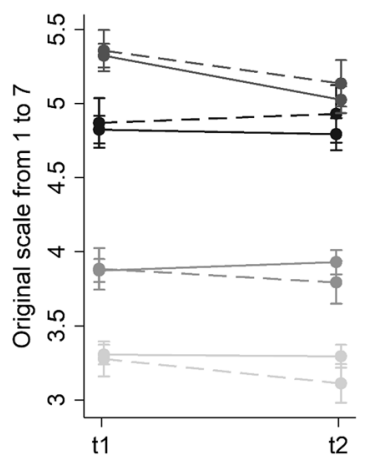

(b) Comprehensive school

vs 2-year pathway

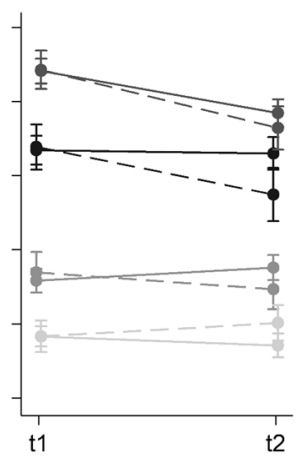

(c) 3-year pathway

2-year pathway

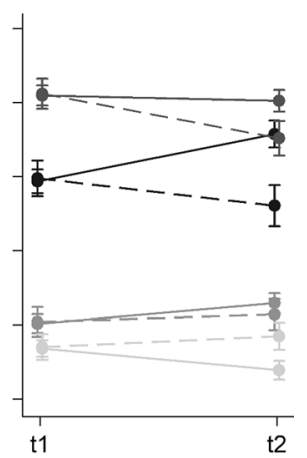

Treatment:

Control:

Intention to study

Attitude

Subjective norm

Perceived behavioural control

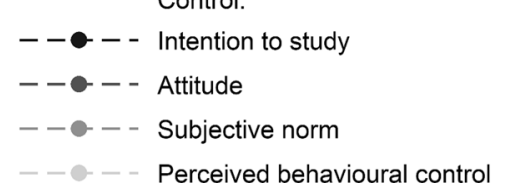

Fig. 3 Development of the intention to study and major factors in different pathways to HE. Note: Treatment group for each comparison indicated by former mention in the illustration title. Mean differences at $\mathrm{t} 1$ indicate a successful matching procedure. Calculations based on multiply imputed $(\mathrm{M}=20)$ datasets. Matching analysis $(\mathrm{NN}+1, \mathrm{c}=0.01)$ conducted on each imputed data set separately and estimation results obtained by Rubin's combination rules (Rubin, 1987). Results of all matching analyses presented in Table 2 of the appendix

HE, cannot be fully confirmed, because the intention to study and the major factors develop similarly at the comprehensive schools and the three-year pathway, and differences can be found between these pathways to HE and the two-year pathway (see Table 6 for the coefficients and robustness checks).

Different effects of social background according to pathway to HE (hypothesis 3) We expected weaker effects of the social background on the intention to study and the major factors at comprehensive schools compared to vocationally oriented pathways to HE. The results of these analyses are shown in Fig. 4, and the charts must be read as follows: The dots show the standardized differences in the intention to study and the major factors of a particular social group in different pathways to HE. The question whether the effects of social background differ depending on the pathway can be answered by comparing the dots of the same colour in the same chart. If their confidence intervals overlap, these differences are not significant. The results derived from charts a) and b) indicate that the development of these variables is the same for pupils from less privileged and from privileged backgrounds at vocationally oriented and comprehensive schools. Similarly, no differential effects of social background can be found for the comparison of the two-year and three-year pathways to HE in chart c) (see Tables 7, 8 , and 9 for more information). Thus, hypothesis 3 cannot be confirmed. 
(a) Comprehensive school 3-year pathway

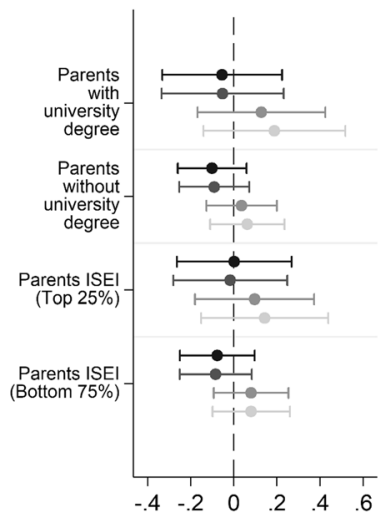

(b) Comprehensive school vs 2-year pathway

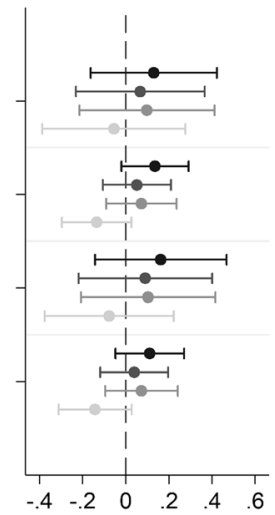

(c) Comprehensive school 2-year pathway

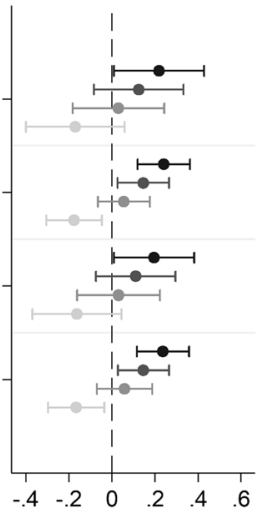

Conditional average treatment effect on the treated (CATT)

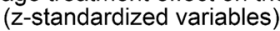

- Intention to study

- Attitude

- Subjective norm

Perceived behavioural control

Fig. 4 Differences in the intention to study and major factors due to different pathways to HE and social background. Note: Calculations based on multiply imputed $(M=20)$ datasets. Matching analysis $(\mathrm{NN}+1, \mathrm{c}=0.01)$ conducted on each imputed data set separately and estimation results obtained by Rubin's combination rules (Rubin, 1987)

\section{Discussion}

In this paper, we were in general concerned with the development of the intention to study in upper secondary education and the motivational factors that precede this intention at comprehensive schools and in vocationally oriented pathways to HE. In Germany these routes to HE were introduced in the 1960s and the 1970s, one of the important reasons being to give access to HE to more pupils from different social backgrounds than had previously been the case and therefore to contribute to a reduction of social inequalities in the transition to $\mathrm{HE}$.

We assumed that (1) social background has an effect on the development of the intention to study due to perceived behavioural control and attitudes (= two of three major factors), (2) the intention to study develops more favourably at comprehensive schools compared to vocationally oriented pathways to HE due to differences in the development of attitudes towards HE, subjective norms and perceived behavioural control, and (3) the effects of social background are less pronounced at comprehensive schools than in vocationally oriented pathways due to differences in the development of the major factors. Our results referring to hypothesis 1) show that the intention to study at the end of upper secondary education is largely determined by the major factors and the intention to study at the beginning of upper secondary education. However, holding constant the major factors and the intention to study at $\mathrm{t} 1$, the attitudes towards $\mathrm{HE}$ and the subjective norms of pupils from non-privileged backgrounds develop less favourably than those of pupils from privileged 
backgrounds. This study thus contributes to confirming the results of other studies that also found a widening gap in the intention to study among pupils from different backgrounds in the later years of secondary education (Croll, 2009; Finger, 2016; Gutman \& Schoon, 2012). Moreover, we found that perceived social pressure and, most importantly, the pupils' perception of the extent to which he/she can achieve his/her goals (=attitude towards HE) but not the perceived obstacles which can prevent pupils from entering HE (= perceived behavioural control) were associated with the widening gap in the intention to study between pupils from different social backgrounds (see also Daniel \& Watermann, 2018; Finger, 2016).

Our findings partly supported the assumption that the intention to study develops more favourably at comprehensive schools than in the vocationally oriented pathways (hypothesis 2): The three-year pathway does not differ from comprehensive schools regarding its impact on the intention to study and on the motivational factors. However, the intention to study of pupils in the two-year pathway decreased compared to that of pupils at comprehensive schools. Furthermore, the comparison of three-year and two-year pathways indicated an increasing gap in the attitude towards HE and perceived behavioural control to the detriment of two-year pathways. Pupils who attend two-year instead of three-year pathways seem increasingly less convinced of the benefits of $\mathrm{HE}$, and their perception of expectations related to $\mathrm{HE}$ of relevant others decreases. Therefore, the results suggest that different vocationally oriented pathways do not have the same impact on the intention to study. We assumed that a decrease in the attitudes and subjective norms may be the result of a weak college-going-culture, which in two-year pathways is characterized by low expectations of teachers and counselling staff and few opportunities for study counselling and guidance (Schuchart, 2019). Furthermore, the pre-analyses for PSM indicated that compared to other pathways at $\mathrm{t} 1$, two-year pathways have a less favourable pupil body in terms of (among others) the aggregated intention to study and motivational factors. Pupils may therefore also demotivate each other because they have low expectations and attitudes in the course of upper secondary education. In all, it seems that two-year pathways divert even previously ambitious pupils from HE.

Although the goal of both three-year and two-year pathways is to prepare pupils for vocational training, the pupil composition is different in terms of average intention to study and its motivational factors. Furthermore, as the pre-analyses for PSM showed, the cognitive ability, academic performance and educational family background of pupils in three-year pathways is similar to that of pupils at comprehensive schools. Academic norms and the expectations of staff as part of the college-going culture may react to this pupil composition and are clearly higher than in two-year pathways (Schuchart, 2019). Since the majority of pupils in three-year pathways attended non-academic school types during lower secondary education which are not oriented towards HE, it is perhaps not surprising that there is an increase in their intention to study after entering a new and more study-oriented context in upper secondary education.

Finally, we expected that the increasing gap between pupils from privileged and non-privileged backgrounds would be more pronounced for vocationally oriented pathways to HE than for those at the comprehensive schools (hypothesis 3). This 
hypothesis could not be confirmed. Differences between social groups were the same in all pathways. Considering the results for hypothesis 2, we can state: The intention to study decreases only in two-year pathways, but these pathways seem to divert pupils from entering HE regardless of their social background. This pathway seems to be much more weakly oriented towards HE, and it may instead orient its pupils towards vocational training options, regardless of their social background.

\subsection{Limitations}

This study has some limitations. (1) In order to analyse the effects of different pathways to HE on the intention to study and its motivational factors, we used PSM. Although PSM overcomes some problems that arise in regression-based analyses, neither approach deals with unobserved heterogeneity. In order to eliminate (potential) selection bias, using longitudinal data with several survey periods before and after pathway choice would be more appropriate. (2) A panel survey with more points in time would also overcome another limitation of our study-since our data were restricted to upper secondary education, they do not provide any information on the extent to which the intention to study of pupils from different social groups was already formed by school types in lower secondary education. In stratified school systems, the exposure to certain institutional contexts over many years in lower secondary education could well be more important than relatively brief exposure to institutional contexts in upper secondary education. Under the influence of their social background and the socialization context (e.g. the expectations of peers and teachers) of lower secondary school types, children may have ruled out vocational and educational options that they did not perceive as appropriate. The transition to different non-traditional pathways in upper secondary education may therefore also reflect educational intentions that had already been formed in lower secondary education and that could only be altered to a small extent in upper secondary education. (3) The transition to HE was not part of this study. Behaviour is not completely regulated by rationally accessible considerations such as intentions and motivational factors, and social background characteristics have an effect on educational decisions even if intentions are controlled for (Schuchart, 2012). Background-specific socialization effects of different pathways to HE may become more clearly visible if not only the intention to study but also the decision for HE is considered. 


\subsection{Conclusions}

The starting point of this study was the findings of other studies, namely that nontraditional, in particular vocationally oriented pathways to HE increase social inequalities in the transition to $\mathrm{HE}$, and that this can be the result of selection and socialization effects of these pathways. Most of the previous studies have not analysed these effects any further. In the present study, we focused on socialization effects and investigated how the intention to study of pupils from different social backgrounds in non-traditional-academic and vocationally oriented-pathways in Germany develops. Our results indicate that in both academic and three-year vocationally oriented pathways pupils are encouraged to maintain and even strengthen their intention to study, whereas pupils in two-year pathways are diverted from HE, regardless of social background. This means that only one of the non-traditional pathways - though a quantitatively very important one-contributes to social inequalities by weakening the control beliefs and attitudes towards HE, and, as a result, the intention to study of its pupils, who are more likely than in other educational pathways to come from socially disadvantaged backgrounds. Since we did not consider characteristics of the pupil composition and college going culture of schools, we do not know whether the decrease in the intention to study can be attributed to an active diversion from HE (and maybe towards a vocational training option) or rather to a simple absence of peer expectations and helpful study preparation and guidance. Further studies should focus on the processes which divert from HE those pupils who are in vocationally oriented pathways which have a rather unfavourable pupil composition.

\section{Appendix}

See Tables 2, 3, 4, 5, 6, 7, 8, and 9.

See Figs. 5, 6, and 7. 


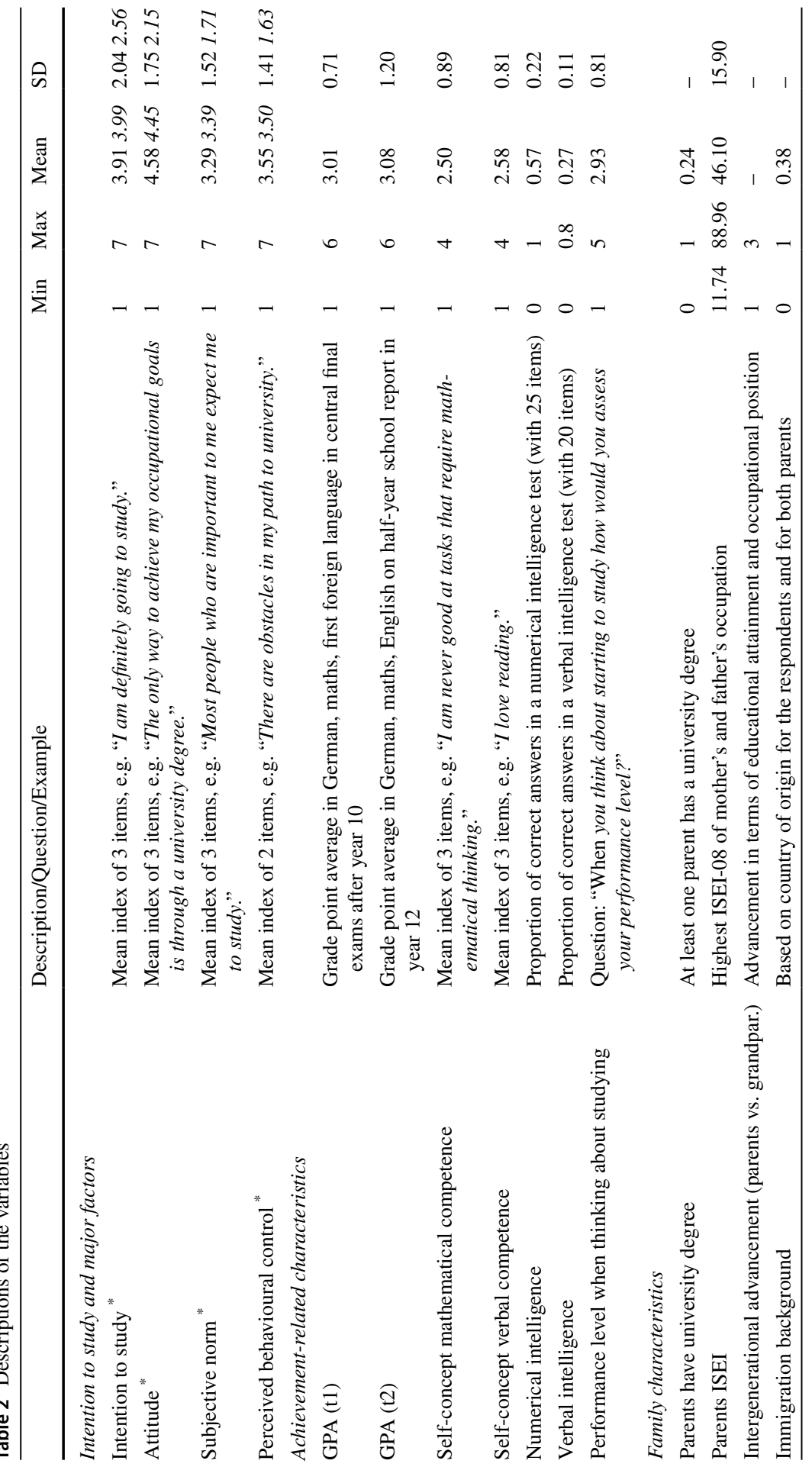




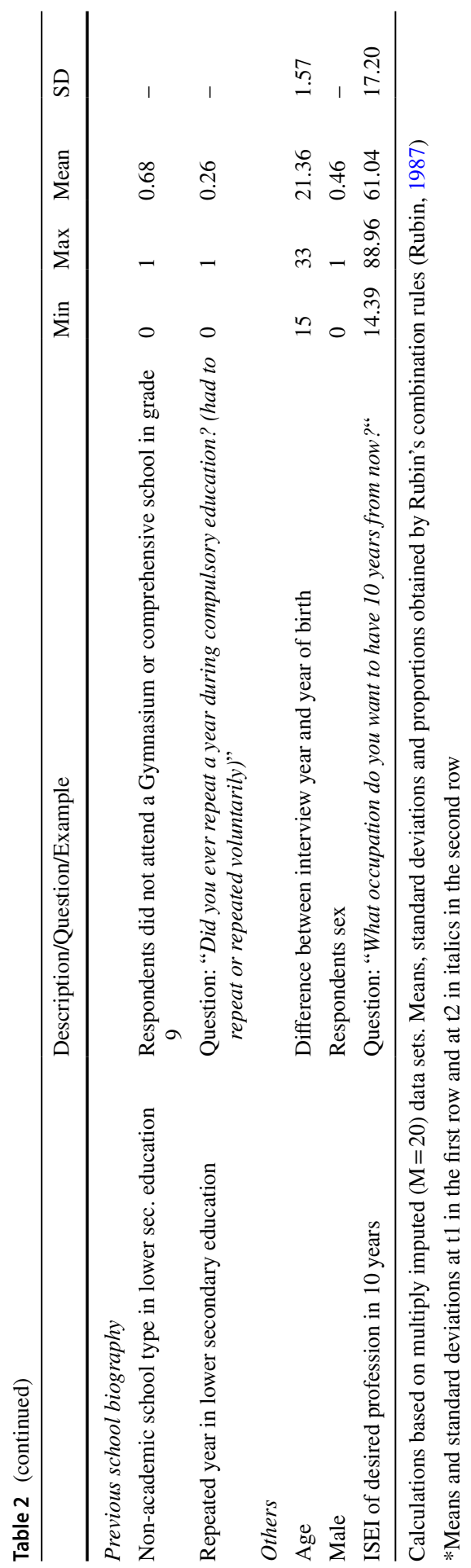




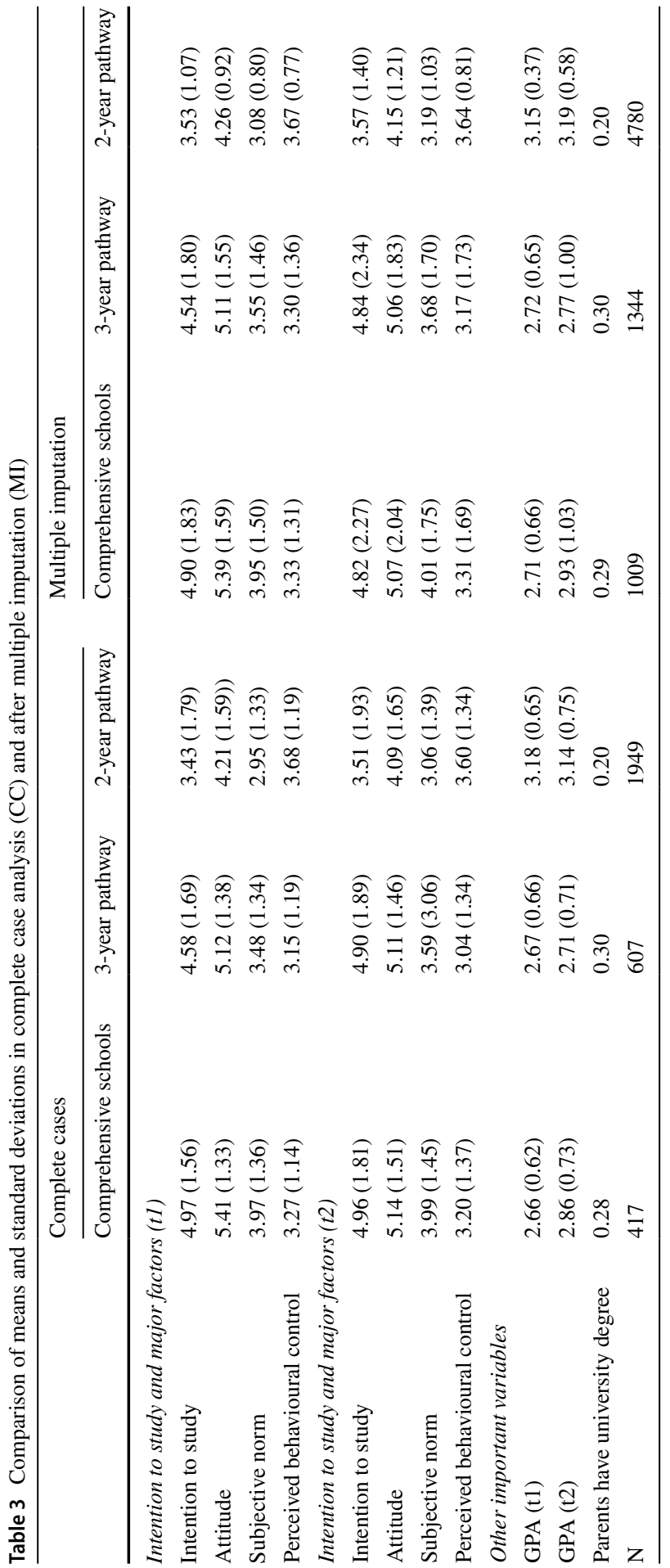




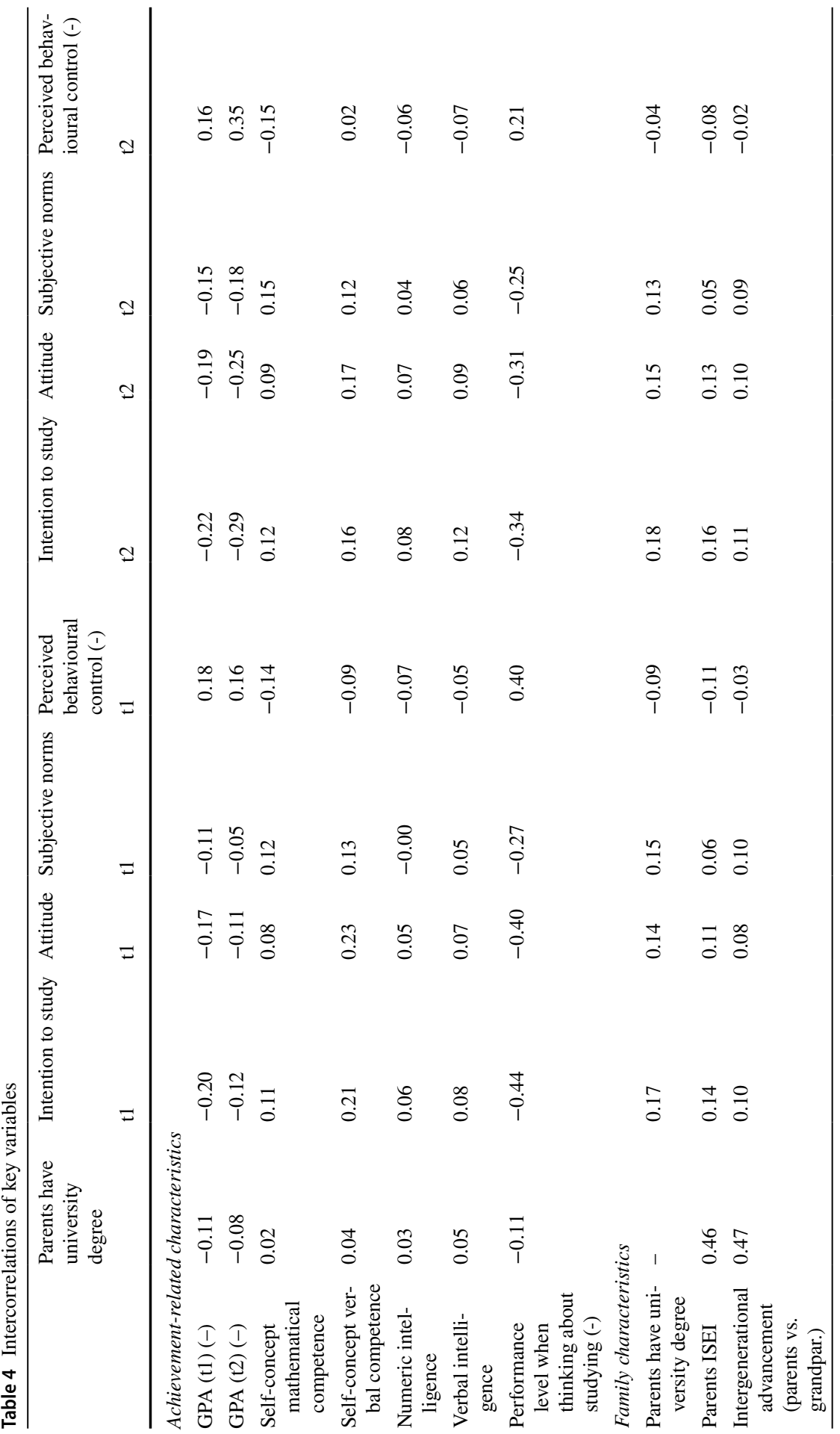




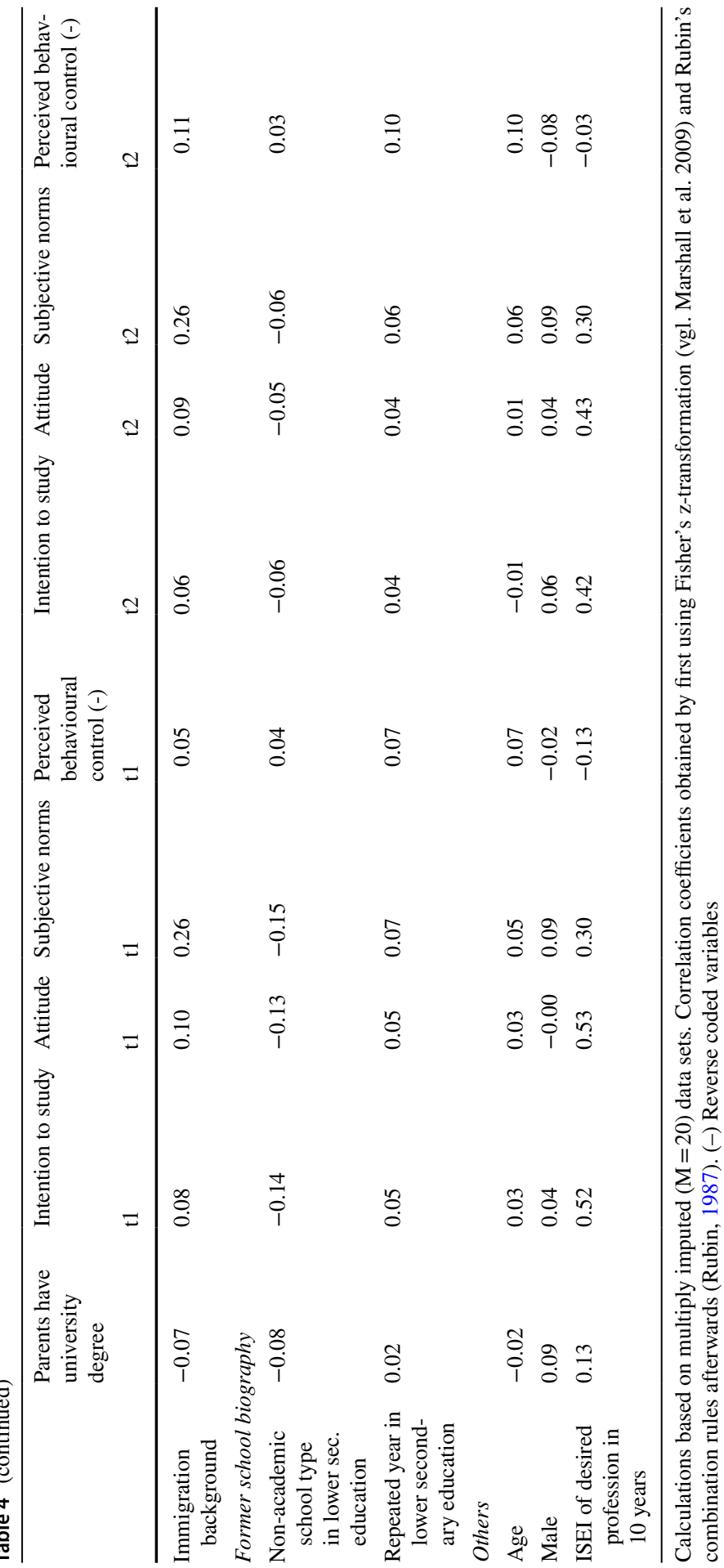




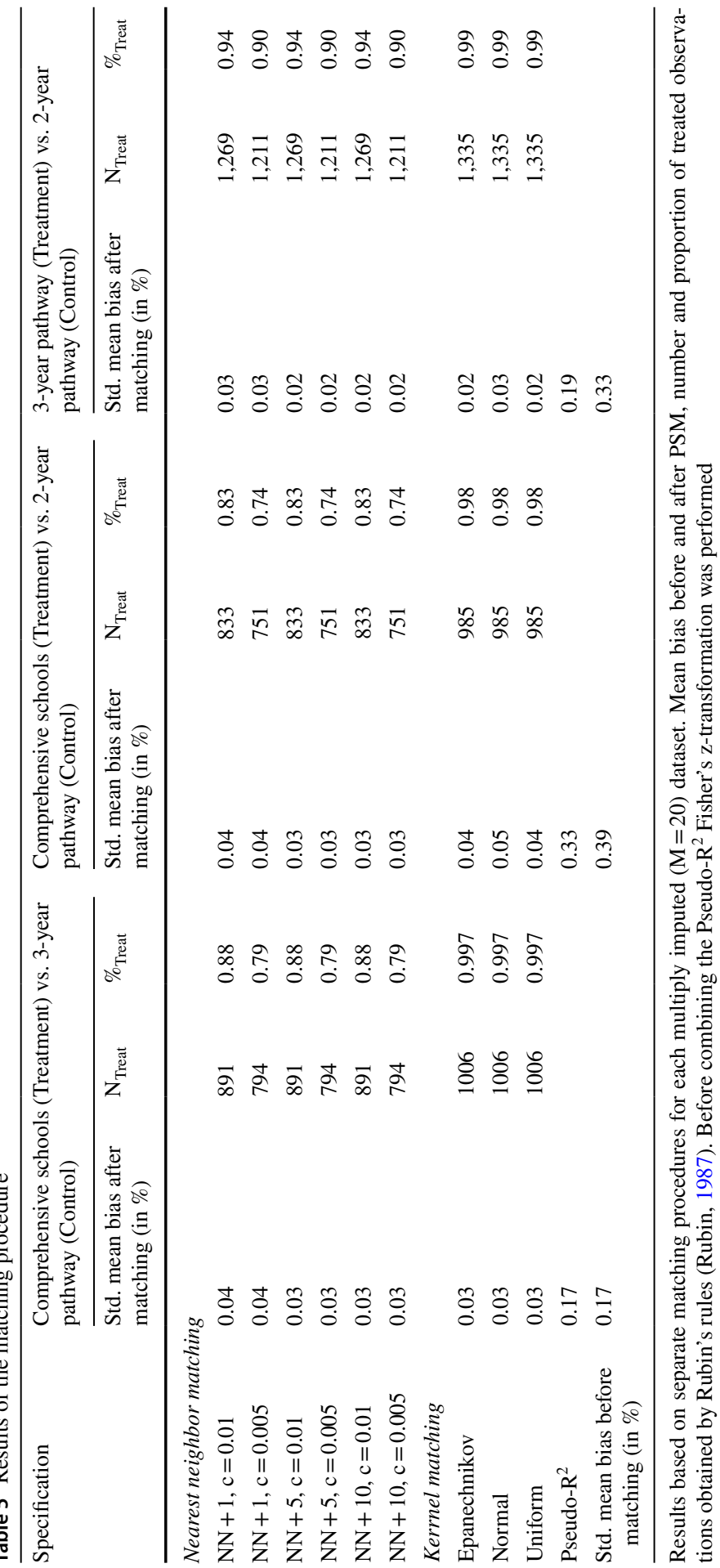




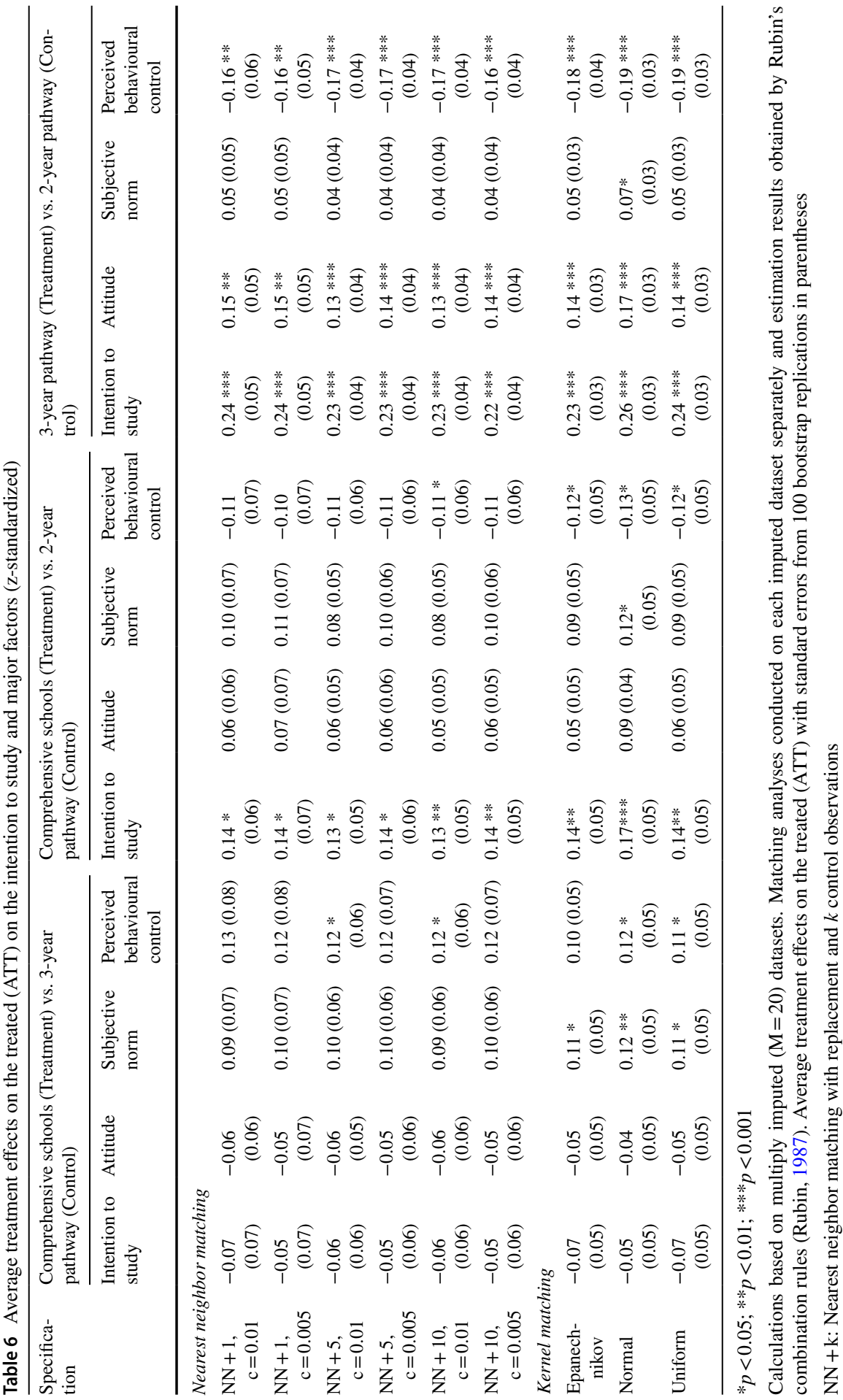




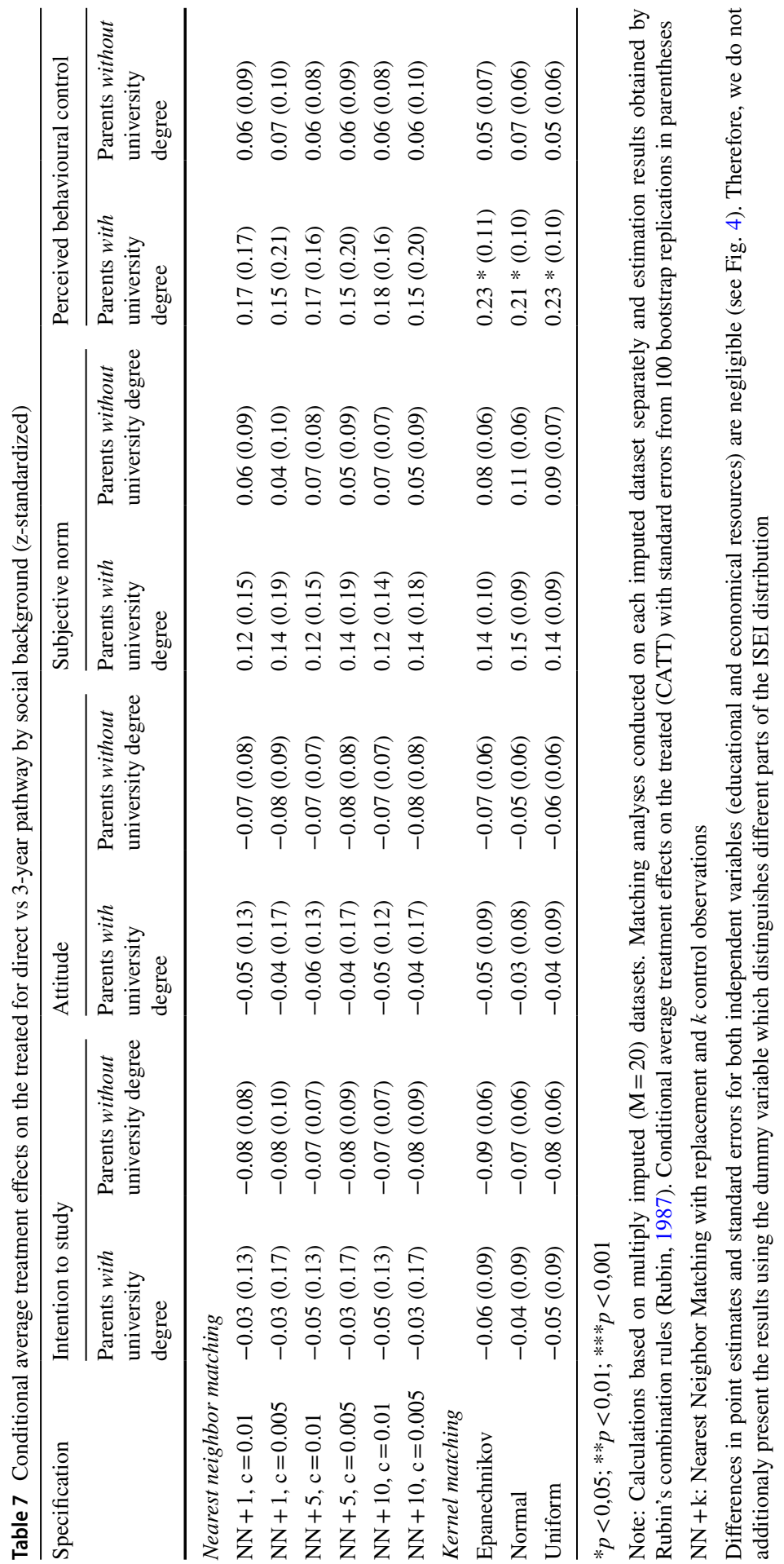




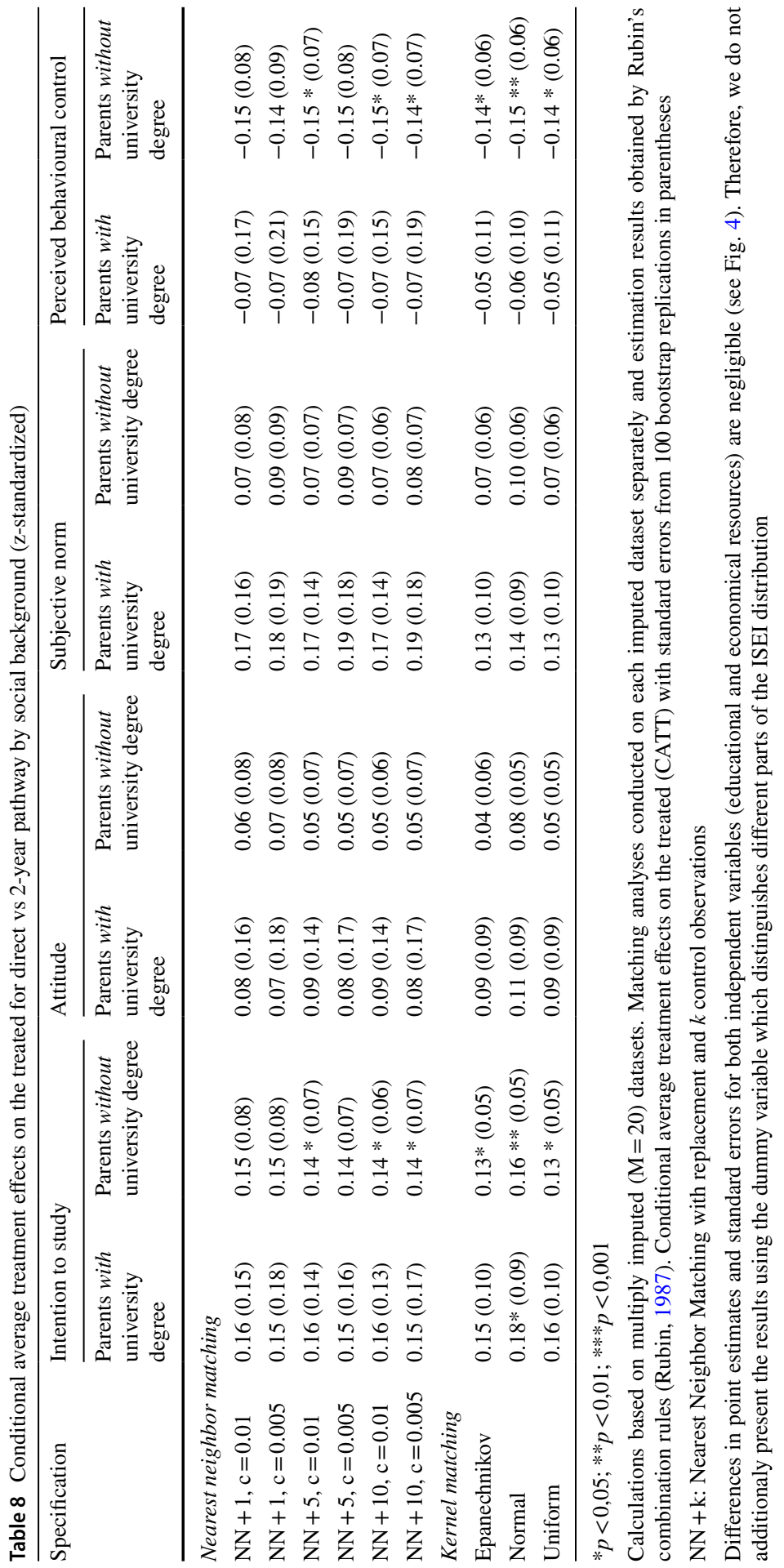




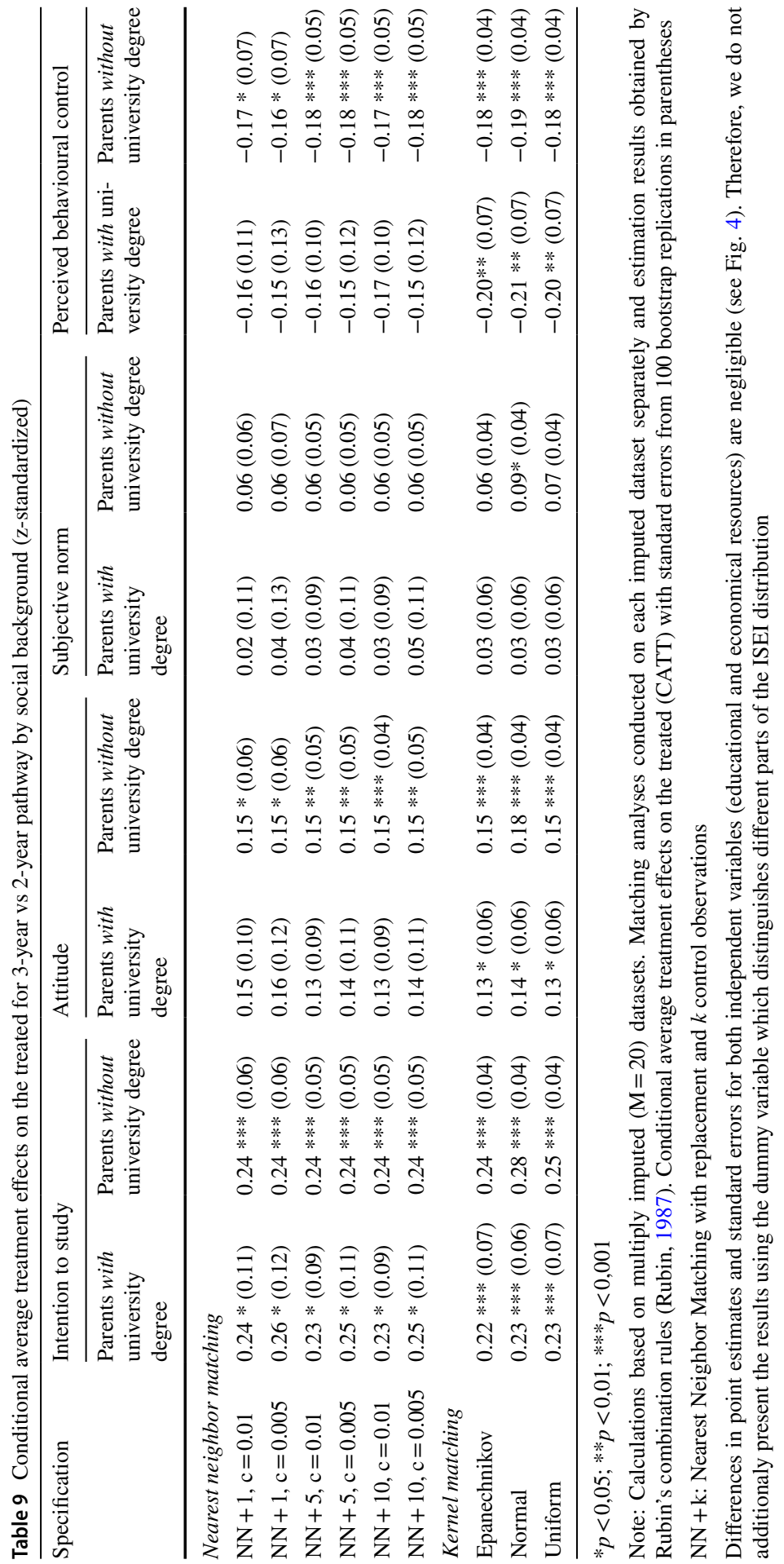



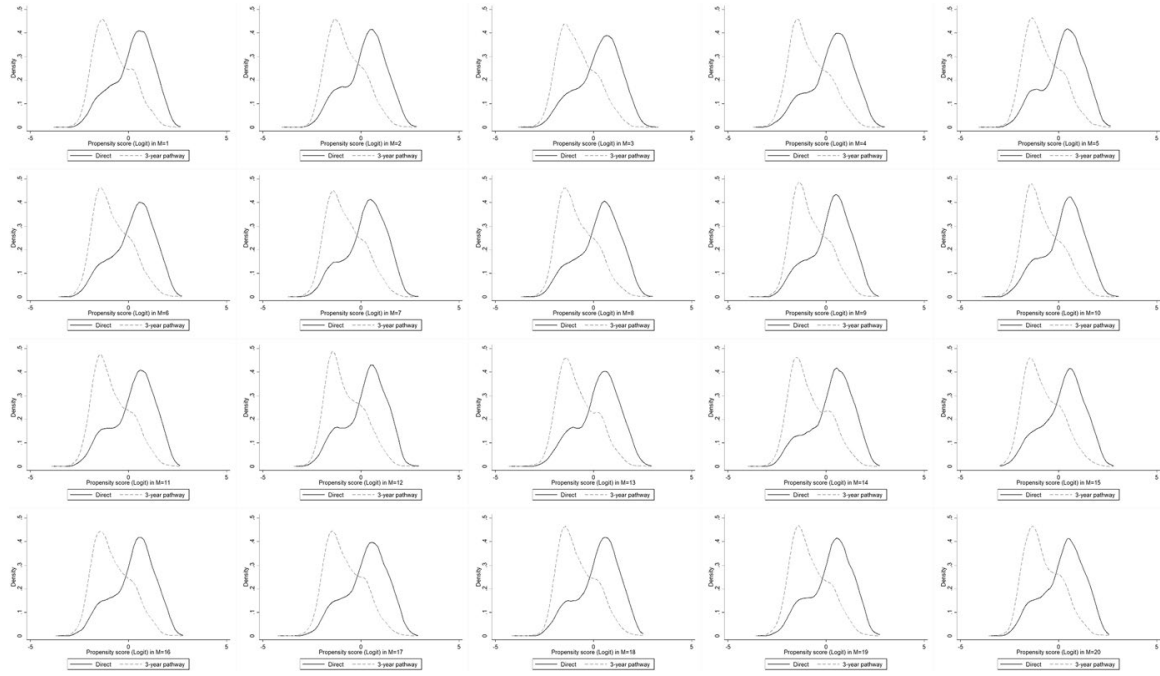

Fig. 5 Distribution of propensity scores for pupils in comprehensive schools and three-year pathways in multiply imputed datasets
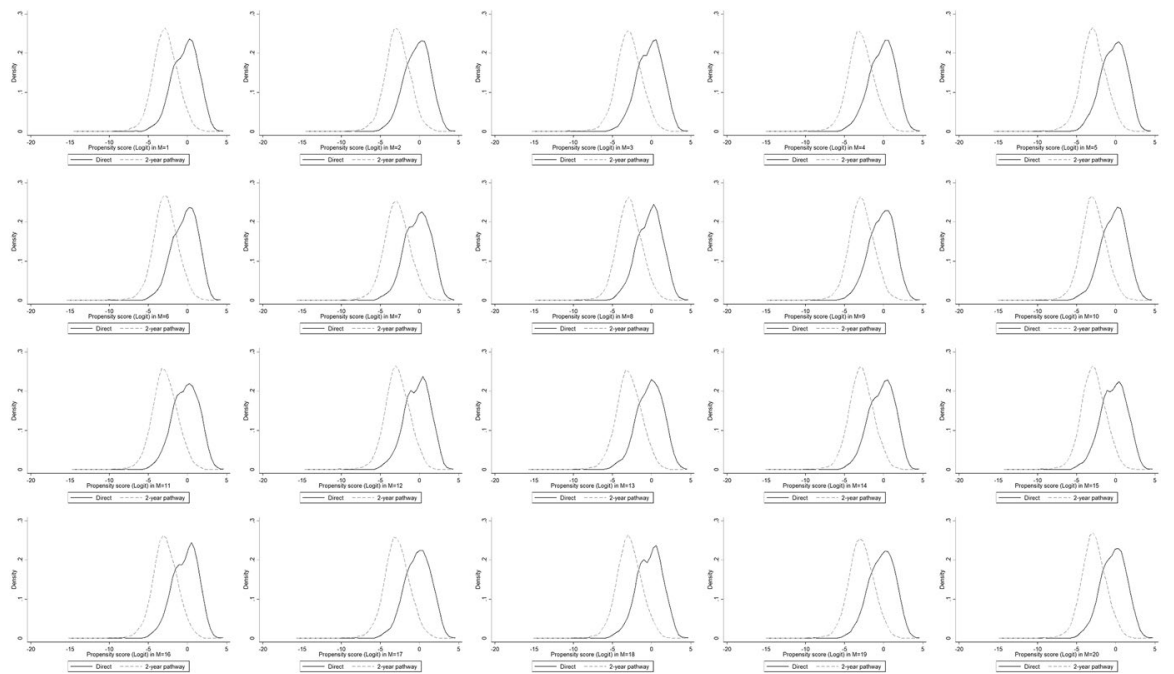

Fig. 6 Distribution of propensity scores for pupils in comprehensive schools and two-year pathways in multiply imputed datasets 

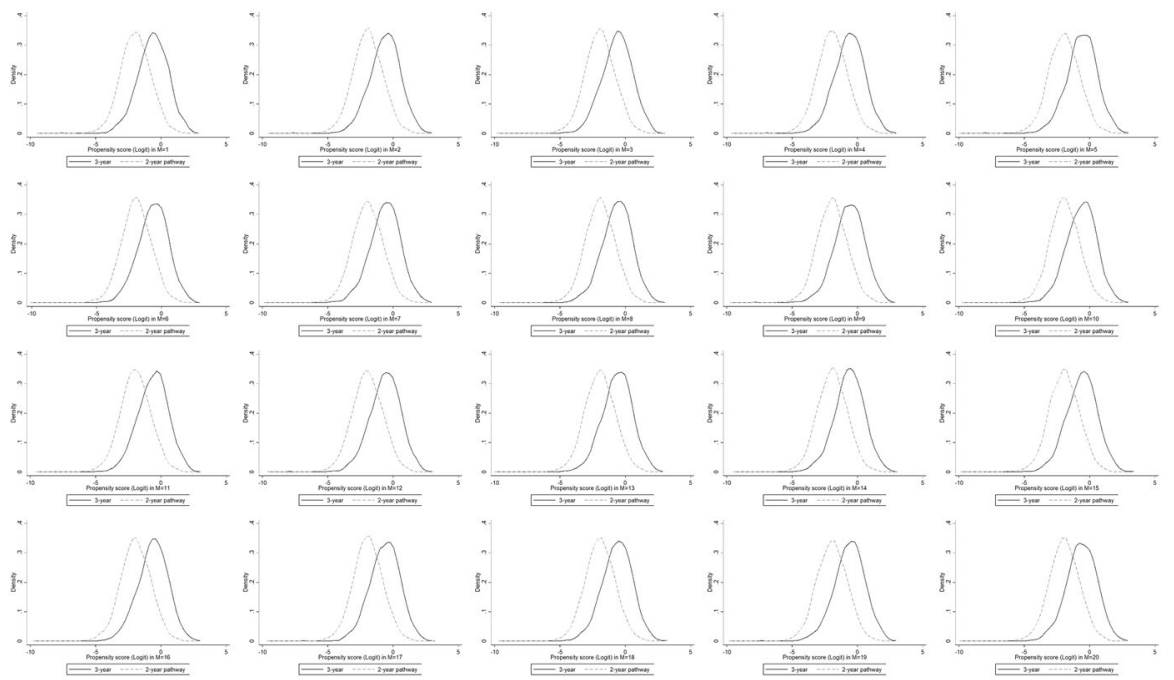

Fig. 7 Distribution of propensity scores for pupils in three-year and two-year pathways in multiply imputed datasets

Funding Open Access funding enabled and organized by Projekt DEAL. Bundesministerium für Bildung und Forschung, 01JC1109, Claudia Schuchart/Petra Buchwald.

Open Access This article is licensed under a Creative Commons Attribution 4.0 International License, which permits use, sharing, adaptation, distribution and reproduction in any medium or format, as long as you give appropriate credit to the original author(s) and the source, provide a link to the Creative Commons licence, and indicate if changes were made. The images or other third party material in this article are included in the article's Creative Commons licence, unless indicated otherwise in a credit line to the material. If material is not included in the article's Creative Commons licence and your intended use is not permitted by statutory regulation or exceeds the permitted use, you will need to obtain permission directly from the copyright holder. To view a copy of this licence, visit http://creativecommons.org/licen ses/by/4.0/.

\section{References}

Ajzen, I. (1988). Attitudes, personality and behavior. Open University Press.

Ajzen, I. (1991). The theory of planned behavior. Organizational Behavior and Human Decision Processes, 50, 179-211.

Ajzen, I., \& Madden, T. J. (1986). Prediction of goal-directed behavior. Attitudes, intentions, and perceived behavioral control. Journal of Experimental Social Psychology, 22, 453-474.

Alexander, K. L., Bozick, R., \& Entwisle, D. R. (2008). Warming up, cooling out, or holding steady? Persistence and change in educational expectations after high school. Sociology of Education, 81, 371-396.

Barone, C., Schizzerotto, A., Abbiati, G., \& Argentin, G. (2017). Information barriers, social inequality, and plans for higher education. Evidence from a field experiment. European Sociological Review, $33,84-86$.

Barone, C., Triventi, M., \& Assirelli, G. (2018). Explaining social inequalities in access to university. A test of rational choice mechanisms in Italy. European Sociological Review, 34, 554-569.

Becker, R., \& Hecken, A. E. (2009). Higher education or vocational training? Acta Sociologica, 52, $25-45$. 
Blau, P. (1960). A theory of social integration. American Journal of Sociology, 65(6), 545-556.

Bol, T., \& van de Werfhorst, H. G. (2013). Educational systems and the trade-off between labor market allocation and equality of educational opportunity. Comparative Education Review, 57, 285-308.

Breen, R., \& Jonsson, J. O. (2000). Analyzing educational careers. A multinomial transition model. American Sociological Review, 65, 754-772.

Brint, S. and Karabel, J. (1989). The diverted dream. Community colleges and the promise of educational opportunity in America, 1900-1985. New York: Oxford University Press.

Buchholz, S., \& Schier, A. (2015). New game, new chance? Social inequalities and upgrading secondary school qualifications in West Germany. European Sociological Review, 31, 603-615.

Buchmann, C., \& Dalton, B. (2002). Interpersonal influences and educational aspirations in 12 countries. The importance of institutional context. Sociology of Education, 75, 99-122.

Buchmann, C., \& Park, H. (2009). Stratification and the formation of expectations in highly differentiated educational systems. Research in Social Stratification and Mobility, 27, 245-267.

Bukodi, E., \& Goldthorpe, J. H. (2013). Decomposing social origins: The effects of parents' class, status, and education on the educational attainment of their children. European Sociological Review, 29(5), 1024-1039.

Byun, S.-Y., Meece, J. L., Irvin, M. J., \& Hutchins, B. C. (2012). The role of social capital in educational aspirations of rural youth. Rural Sociology, 77, 355-379.

Caliendo, M., \& Kopeinig, S. (2008). Some practical guidance for the implementation of propensity score matching. Journal of Economic Surveys, 22, 31-72.

Carpenter, J. R., \& Kenward, M. G. (2014). Multiple imputation and its applications. John Wiley \& Sons.

Castleman, B. L., \& Page, L. C. (2013). The not-so-lazy days of summer. Experimental interventions to increase college entry among low-income high school graduates. New Directions for Youth Development, 140, 77-97.

Constantine, J. M., Seftor, N. S., Martin, E. S., Silva, T., \& Myers, D. (2006). A Study of the effect of talent search on secondary and postsecondary outcomes in Florida, Indiana, and Texas. U.S. Department of Education.

Croll, P. (2009). Educational participation post-16. A longitudinal analysis of intentions and outcomes. British Journal of Educational Studies, 57, 400-416.

Daniel, A., \& Watermann, R. (2018). The role of perceived benefits, costs, and probability of success in students' plans for higher education. A quasi-experimental test of rational choice theory. European Sociological Review, 34, 539-553.

Davis, L. E., Ajzen, I., Saunders, J., \& Williams, T. (2002). The decision of African American students to complete high school. An application of the theory of planned behavior. Journal of Educational Psychology, 94, 810-819.

Dewberry, C., \& Jackson, D. J. R. (2018). An application of the theory of planned behavior to student retention. Journal of Vocational Behavior, 107, 100-110.

Dreeben, R., \& Barr, R. (1988). Classroom composition and the design of instruction. Sociology of Education, 61(3), 129-142.

Ehlert, M., Finger, C., Rusconi, A., \& Solga, H. (2017). Applying to college: Do information deficits lower the likelihood of college-eligible students from less-privileged families to pursue their college intentions? Evidence from a field experiment. Social Science Research, 67, 193-212.

Enders, C. K. (2010). Applied missing data analysis. Guilford Press.

Engberg, M. E., \& Gilbert, A. J. (2014). The counseling opportunity structure: Examining correlates of four-year college-going rates. Research in Higher Education, 55(3), 219-244.

Erickson, L. D., McDonald, S., \& Elder, G. H., Jr. (2009). Informal mentors and education. Complementary or compensatory resources? Sociology of Education, 82, 344-367.

Erikson, R., \& Jonsson, J. O. (1996). Can education be equalized? The Swedish case in comparative perspective. Westview Press.

Finger, C. (2016). Institutional constraints and the translation of college aspirations into intentions. Evidence from a factorial survey. Research in Social Stratification and Mobility, 46, 112-128.

Fishbein, M. A., \& Ajzen, I. (1975). Belief, attitude, intention and behaviour. An introduction to theory and research. Addison-Wesley Publishing Company.

Gamoran, A. (2010). Tracking and inequality. New directions for research and practice. In M. W. Apple, S. J. Ball, \& L. A. Gandin (Eds.), The Routledge international handbook of the sociology of education (pp. 213-228). Routledge.

Gangl, M. (2010). Nichtparametrische Schätzung kausaler Effekte mittels Matchingverfahren [Non-parametric estimates of casual effects using matching methods]. In C. Wolf \& H. Best (Eds.), Handbuch 
der sozialwissenschaftichen Datenanalyse [Handbook for data analysis in the social science] (pp. 931-961). VS Verlag für Sozialwissenschaften.

Ganzeboom, H. B. G., \& Treiman, D. J. (2003). Three internationally standardised measures for comparative research on occupational status. In J. H. P. Hoffmeyer-Zlotnik \& C. Wolf (Eds.), Advances in cross-national comparison. A European working book for demographic and socio-economic variables (pp. 159-193). New York: Springer.

Griga, D., \& Hadjar, A. (2013). Migrant background and higher education participation in Europe. The effect of the educational systems. European Sociological Review, 30, 275-286.

Gutman, L. M., \& Schoon, I. (2012). Correlates and consequences of uncertainty in career aspirations. Gender differences among adolescents in England. Journal of Vocational Behavior, 80, 608-618.

Hadjar, A., \& Gross, C. (Eds.). (2016). Education systems and inequalities. International comparisons. Policy Press.

Haller, A. (1968). On the concept of aspiration. Rural Sociology, 33, 484-487.

Heine, C., Quast, H. and Beuße, M. (2010). Studienberechtigte 2008 ein halbes Jahr nach Schulabschluss. Übergang in Studium, Beruf und Ausbildung [Persons entitled to study in 2008 six months after graduating school. Transition to university, occupation and training]. Hannover: HIS.

Heller, K. A., Gaedike, A.-K., \& Weinländer, H. (1985). Kognitiver Fähigkeitstest (KFT 4-13+) [Cognitive ability test]. Beltz.

Hill, L. D. (2008). School strategies and the "College-Linking" process: Reconsidering the effects of high schools on college enrollment. Sociology of Education, 81(1), 53-76.

Hillmert, S., \& Jacob, M. (2003). Social inequality in higher education. Is vocational training a pathway leading to or away from university? European Sociological Review, 19, 319-334.

Hillmert, S., \& Jacob, M. (2010). Selections and social selectivity on the academic track. A life-course analysis of educational attainment in Germany. Research in Social Stratification and Mobility, 28, 59-76.

Holm, A., Jæger, M. M., Karlson, K. B., \& Reimer, D. (2013). Incomplete equalization. The effect of tracking in secondary education on educational inequality. Social Science Research, 42, 1431-1442.

Ichou, M., \& Vallet, L.-A. (2011). Do all roads lead to inequality? Trends in French upper secondary school analysed with four longitudinal surveys. Oxford Review of Education, 37, 167-194.

Kerckhoff, A. C., Haney, L. B., \& Glennie, E. (2001). System effects on educational achievement. A British-American Comparison. Social Science Research, 30, 497-528.

Kerr, S. P., Pekkarinen, T., Sarvimäki, M. and Uusitalo, R. (2015). Post-secondary education and information on labor market prospects. A randomized field experiment. Bonn.

Leuze, K. (2011). How structure signals status. Institutional stratification and the transition from higher education to work in Germany and Britain. Journal of Education and Work, 24, 449-475.

Maaz, K. (2006). Soziale Herkunft und Hochschulzugang. Effekte institutioneller Öffnung im Bildungssystem [Social background and access to higher education. Effects of institutional opening in the education system]. Wiesbaden: VS Verlag für Sozialwissenschaften.

Marsh, H. W. (1992). Self description questionnaire (SDQ) II: A theoretical and empirical basis for the measurement of multiple dimensions ofadolescent self-concept. An interim test manual and a research monograph. Macarthur, New South Wales, Australia: University of Western Sidney.

McDonough, P. M. (1997). Choosing colleges: How social class and schools structure opportunity. State University of New York Press.

Morgan, S. L. (2006). Expectations and aspirations. In Ritzer, G. (Ed), The Blackwell Encyclopedia of Sociology. Malden, MA: Wiley-Blackwell, pp. 1528-1531.

Müller, S., \& Schneider, T. (2013). Educational pathways and dropout from higher education in Germany. Longitudinal and Life Course Studies, 4, 218-241.

Müller, W., \& Shavit, Y. (1998). The institutional embeddedness of the stratification process. Study of qualifications and occupations in thirteen countries. In Y. Shavit \& W. Müller (Eds.), From school to work. A comparative study of educational qualifications and occupational destinations (pp. 1-48). Clarendon Press.

Niepel, C., Burrus, J., Greiff, S., Lipnveich, A. A., Brenneman, M. W., \& Roberts, R. D. (2018). Students' beliefs and attitudes toward mathematics across time. A longitudinal examination of the theory of planned behavior. Learning and Individual Differences, 63, 24-33.

Palardy, G. J. (2015). High school socioeconomic composition and student college choice: Multilevel mediation via school organizational habitus, practices, and peer influences. School Effectiveness and School Improvement, 26(3), 398-423. 
Parker, P. D., Jerrim, J., Schoon, I., \& Marsh, H. W. (2016). A multination study of socioeconomic inequality in expectations for progression to higher education. The role of between-school tracking and ability stratification. American Educational Research Journal, 53, 6-32.

Perna, L. W. (2008). The role of college counseling in shaping college opportunity. Variations across high schools. The Review of Higher Education, 31, 131-159.

Peter, F., \& Zambre, V. (2017). Intended college enrollment and educational inequality. Do students lack information? Economics of Education Review, 60, 125-141.

Petzold, K., \& Moog, P. (2018). What shapes the intention to study abroad? An experimental approach. Higher Education, 75, 35-54.

Pfeffer, F. T. (2008). Persistent inequality in educational attainment and its institutional context. European Sociological Review, 24, 543-565.

Reay, D. (1998). 'Always knowing' and 'never being sure': Familial and institutional habituses and higher education choice. Journal of Education Policy, 13(4), 519-529.

Reay, D., David, M. E. and Ball, S. J. (2001). Making a difference? Institutional habituses and higher education choice. Sociological Research Online, $\mathbf{5}$.

Reimer, D., \& Pollak, R. (2010). Educational expansion and its consequences for vertical and horizontal inequalities in access to higher education in West Germany. European Sociological Review, 26, 415-430.

Robinson, K. J., \& Roksa, J. (2016). Counselors, information, and high school college-going culture: Inequalities in the college application process. Research in Higher Education, 57(7), 845-868.

Retelsdorf, J., Becker, M., Köller, O., \& Möller, J. (2012). Reading development in a tracked school system. A longitudinal study over 3 years using propensity score matching. British Journal of Educational Psychology, 82, 647-671.

Rosenbaum, J. E. (2001). Beyond college-for-all. Career paths for the forgotten half. Russel Sage Foundation.

Rosenbaum, P. R., \& Rubin, D. B. (1983). Assessing sensitivity to an unobserved binary covariate in an observational study with binary outcome. Journal of the Royal Statistical Society. Series B, 45, 212-218.

Roth, T. (2017). Interpersonal influences on educational expectations. New evidence for Germany. Research in Social Stratification and Mobility, 48, 68-84.

Rubin, D. B. (1987). Multiple imputation for nonresponse in surveys. John Wiley \& Sons.

Rubin, D. B. (Ed.). (2006). Matched sampling for causal effects. Cambridge University Press.

Schindler, S. (2014). Wege zur Studienberechtigung - Wege ins Studium? Eine Analyse sozialer Inklusions- und Ablenkungsprozesse [Pathways to university entrance qualification - Pathways to study? An analysis of social inclusion and diversion processes]. Springer VS.

Schindler, S. (2017). School tracking, educational mobility and inequality in German secondary education. Developments across Cohorts. European Societies, 19, 28-48.

Schindler, S., \& Lörz, M. (2012). Mechanisms of social inequality development. Primary and secondary effects in the transition to tertiary education between 1976 and 2005. European Sociological Review, 28, 647-660.

Schindler, S., \& Reimer, D. (2010). Primäre und sekundäre Effekte der sozialen Herkunft beim Übergang in die Hochschulbildung [Primary and secondary effects of social origin in the transition to higher education]. Kölner Zeitschrift Für Soziologie Und Sozialpsychologie, 62, 623-653.

Schneider, S. L., \& Tieben, N. (2011). A healthy sorting machine? Social inequality in the transition to upper secondary education in Germany. Oxford Review of Education, 37(2), 139-166.

Schuchart, C. (2012). Upward mobility among secondary education students: The decision to obtain a better certificate. European Journal of Psychology of Education, 28, 201-221.

Schuchart, C. (2019). Kulturen der Studienorientierung? Einzelschulische und schulstrukturelle Determinanten der Studienabsicht in der Sekundarstufe II [Cultures of orientation to university studies? Single-school and school-structural determinants of the intention to study at upper secondary level]. Zeitschrift Für Pädagogik, 1, 120-145.

Schuchart, C., \& Schimke, B. (2019). Lohnt sich das Nachholen eines Schulabschlusses? Alternative Wege zur Hochschulreife und ihre Arbeitsmarkterträge [Is it worthwhile to catch up on a highschool diploma? Alternative paths to higher education entrance qualification and their labour market returns]. Kölner Zeitschrift Für Soziologie Und Sozialpsychologie, 71, 237-273.

Schulministerium NRW. APO-BK. Bestimmungen der APO-BK [Provisions for the Vocational College Training and Examination Regulations]. http://www.berufsbildung.nrw.de/cms/bildungsga 
enge-bildungsplaene/fachklassen-duales-system-anlage-a/bestimmungen-der-apo-bk/index.html [07.07.2020].

Schulministerium NRW. APO-GOSt-B. Verordnung über den Bildungsgang und die Abiturprüfung in der gymnasialen Oberstufe [Ordinance on the course of education and the Abitur examination in the upper secondary school]. https://www.schulministerium.nrw.de/docs/Recht/Schulrecht/APOen/GYOberstufe-SekII/APO-GOSt.pdf [07.07.2020].

Schüz, B., Li, A.S.-W., Hardinge, A., \& McEachan, R. R. C. (2017). Socioeconomic status as a moderator between physical activity and social cognitions. Systematic review and meta-analysis based on the theory of planned behavior. Psychology of Sport and Exercise, 30, 186-195.

Sewell, W. H., Haller, A. O., \& Portes, A. (1969). The educational and early occupational attainment process. American Sociological Review, 34, 82-92.

Shavit, Y., Arum, R., \& Gamoran, A. (Eds.). (2007). Stratification in higher education. A comparative study. Stanford University Press.

Shavit, Y., \& Müller, W. (2006). Vocational secondary education, tracking, and social stratification. In M. T. Hallinan (Ed.), Handbook of sociology of education (pp. 437-452). Springer.

Statistisches Bundesamt (2018). Bildung und Kultur. Allgemeinbildende Schulen [Education and culture. General education schools]. Wiesbaden: Bundesamt.

Trusty, J. (2000). High educational expectations and low achievement. Stability of educational goals across adolescence. The Journal of Educational Research, 93, 356-365.

van Buuren, S. (2012). Flexible imputation of missing data. CRC Press.

van Buuren, S., Brand, J. P. L., Groothuis-Oudshoorn, C. G. M., \& Rubin, D. B. (2006). Fully conditional specification in multivariate imputation. Journal of Statistical Computation and Simulation, 76, 1049-1064.

Watermann, R. and Maaz, K. (2010). Soziale Herkunft und Hochschulzugang. Eine Überprüfung der Theorie des geplanten Verhaltens [Social background and access to university. A review of the theory of planned behaviour]. In Bos, W., Klieme, E. and Köller, O. (Eds.). Schulische Lerngelegenheiten und Kompetenzentwicklung. Festschrift für Jürgen Baumert [School learning opportunities and competence development. Commemorative publication for Jürgen Baumert]. Münster: Waxmann, pp. 311-329.

Zhang, Y., Haddad, E., Torres, B., \& Chen, C. (2011). The reciprocal relationships among parents' expectations, adolescents' expectations, and adolescents' achievement. A two-wave longitudinal analysis of the NELS Data. Journal of Youth and Adolescence, 40, 479-489.

Publisher's Note Springer Nature remains neutral with regard to jurisdictional claims in published maps and institutional affiliations.

Dr. Claudia Schuchart is a Professor of Educational Science at the University of Wuppertal, School of Education. Her research concerns the development of social and ethnic inequalities in classrooms, schools and the school system.

Benjamin Schimke is a research associate at the University of Wuppertal, School of Education. His research interests are sociology of education, labour market sociology, social inequalities in a life course perspective.

\section{Authors and Affiliations}

\section{Claudia Schuchart $^{1}$ (D) Benjamin Schimke ${ }^{1}$}

Claudia Schuchart

Schuchart@uni-wuppertal.de

1 University of Wuppertal, Gaußstrasse 20, 42105 Wuppertal, Germany 